UNIVERSIDADE DE SÃO PAULO

FACULDADE DE DIREITO

CURSO DE PÓS-GRADUAÇÃO STRICTO SENSU - DOUTORADO EM DIREITO

\title{
REFLEXOS DAS NOVAS TECNOLOGIAS NAS ASSEMbleias De S/A
}

\author{
Candidato: \\ JoÃo Pedro barroso do NASCimento
}

ORIENTADOR:

Erasmo Valladão Azevedo e Novaes França

ÁREA DE CONCENTRAČ̃̃:

DiReITO COMERCIAL

SÃo Paulo, 2020 


\author{
UNIVERSIDADE DE SÃO PAULO \\ FACULDADE DE DIREITO \\ CURSO DE PÓS-GRADUAÇÃO STRICTO SENSU - DOUTORADO EM DIREITO
}

JOÃO PEDRO BARROSO DO NASCIMENTO

\title{
REFLEXOS DAS NOVAS TECNOLOGIAS NAS
}

AsSEMbleias DE S/A

Tese de Doutorado apresentada ao

Departamento de Direito Comercial da

Faculdade de Direito da Universidade de São

Paulo como requisito parcial para a obtenção do grau de doutor, sob a orientação do Professor Associado Dr. Erasmo Valladão Azevedo e

Novaes França

São Paulo, 2020 


\section{Catalogação da Publicação \\ Serviço de Biblioteca e Documentação \\ Faculdade de Direito da Universidade de São Paulo}

NASCIMENTO, João Pedro B. do

Reflexos das Novas Tecnologias nas Assembleias de S/A; João Pedro B. do Nascimento; Orientador: Erasmo Valladão Azevedo e Novaes França -- São Paulo, 2020, p. 293

Tese (Doutorado - Programa de Pós-Graduação em Direito Comercial) - Faculdade de Direito, Universidade de São Paulo, São Paulo, 2020.

1. Direito Societário e Mercado de Capitais. 2. Governança Corporativa. 3. Tecnologia, Inovação e Direito Digital. 4. Assembleias Gerais. 5. Blockchain e Smart Contracts. I. FRANÇA, Erasmo Valladão Azevedo e Novaes, orient. II. Título. 


\section{JOÃO PEDRO BARROSO DO NASCIMENTO}

\section{Reflexos das Novas Tecnologias nas}

\section{Assembleias de S/A}

Tese de Doutorado apresentada ao Departamento de Direito Comercial da Faculdade de Direito da Universidade de São Paulo como requisito parcial para a obtenção do grau de doutor em Direito Comercial.

Ata $n$. /2019.

Aprovada em de 2019.

Banca Examinadora:

Presidente: Prof. Dr. Erasmo Valladão Azevedo e Novaes França

Examinador: Prof. Dr. Marcelo Vieira von Adamek

Examinador: Prof. Dr. Thiago Saddi Tannous

Examinador: Prof. Dr. Luis Felipe Spinelli

Examinador: Prof. Dr. Luiz Daniel Haj Mussi

Examinador: Prof. Dr. Wanderley Fernandes 
“Quem não pensa sobre o futuro resolve o

presente com as ferramentas do passado."

(Anônimo) 


\section{RESUMO}

Ao longo dos últimos anos, relevantes transformações no regime jurídico das Assembleias Gerais e do exercício do direito de voto ocorreram no Brasil e no mundo. É cada vez mais frequente a adoção de sistemas de votação a distância e participação remota em Assembleias Gerais, bem como a utilização de elementos de tecnologia para aperfeiçoar os procedimentos em pedidos públicos de procuração e em outros aspectos das Assembleias Gerais.

Nesse sentido, a LSA foi alterada pela Lei $\mathrm{n}^{\circ} 12.431 / 2011$, que promoveu as inclusões: (i) do artigo 121, parágrafo único, da LSA, a fim de reconhecer e legitimar, nas companhias abertas, a possibilidade de participação e voto a distância dos acionistas em Assembleia Geral; e (ii) do artigo 127, parágrafo único, da LSA, que considera presente em Assembleia Geral o acionista que registrar a sua presença a distância. Adicionalmente, as regulações e atos normativos da CVM também têm sido revistos, destacando-se - por exemplo - a Instrução CVM nº 481/2009, com diversas alterações recentes.

Alguns países modernizaram a forma como as Assembleias Gerais são realizadas, admitindo encontros não presenciais, nos quais a interação entre os participantes do conclave é realizada apenas remotamente.

Entendemos que a adoção de tecnologias nas Assembleias Gerais é bem-vinda e deve ser feita como uma forma de ampliação de horizontes, e não como um limite ao exercício de direitos. Sem prejuízo, somos contrários à redução das Assembleias Gerais a encontros exclusivamente virtuais (não presenciais) onde não ocorram debates e discussões e/ou com limitações de interação entre participantes presenciais.

Tradicionalmente, as Assembleias Gerais desempenham um importante papel, na medida em que permitem que os acionistas se envolvam e monitorem coletivamente os negócios sociais, por meio de 3 (três) funções em especial: (i) Função de Informação: os acionistas recebem da companhia informações sobre relevantes e diversos temas pertinentes à companhia e à sua atividade; (ii) Função de Fórum: é oferecido aos acionistas um local para discussões e formulação de questões pertinentes à companhia; e (iii) Função de Tomada de Decisões: os acionistas reúnem-se para, coletivamente, tomar decisões e formar a vontade social. Estas 3 (três) funções têm sofrido importantes transformações recentes e, 
indiscutivelmente, precisam ser repensadas, a fim de evitar a obsolescência do Direito Societário.

É inconcebível pensar que os avanços tecnológicos não produzirão reflexos nas relações entre os acionistas, os administradores e/ou na dinâmica organizacional das grandes companhias. Diante dessas mudanças, tornam-se essenciais estudos dedicados à compreensão de institutos clássicos do direito societário brasileiro, a partir do cenário da Quarta Revolução Industrial. Portanto, a análise da aplicação das tecnologias às Assembleias Gerais de sociedades anônimas é inovadora e de extrema relevância para a comunidade jurídica e para o mercado de capitais, pois o desenvolvimento tecnológico tem potencial para encurtar distâncias entre acionistas, colaborar para o ativismo societário e contribuir para o combate ao absenteísmo alterando as práticas societárias e, consequentemente, impulsionando mudanças legislativas e jurisprudenciais.

Sendo assim, este trabalho tem como objetivo oferecer as seguintes contribuições originais à ciência jurídica: $(\underline{i)}$ de forma imediata - analisar os reflexos nas Assembleias Gerais das mudanças promovidas pelos mecanismos de voto e participação a distância e, também, pelas modificações nos pedidos públicos de procuração (cf. artigos 121, parágrafo único, e 127, parágrafo único, da LSA e Instrução CVM nº 481/2009); e (ii) de forma mediata - ponderar sobre os potenciais efeitos a serem obtidos com a adoção de tecnologias e mecanismos modernos nas Assembleias Gerais, como blockchains e smart contracts, a fim de reduzir a necessidade de atuação humana em aspectos burocráticos do procedimento assemblear.

Este trabalho também analisará algumas adequações sistêmicas a serem realizadas na legislação societária, de modo a adequá-la ao padrão evolutivo e viabilizar a adoção de tecnologias nas Assembleias Gerais. A relevância do presente trabalho reside na colaboração para compreensão das atuais tendências e novas formas de exercício de direitos de acionistas no âmbito das companhias abertas, de modo a (i) identificar obsolescências na legislação societária atual; e (ii) auxiliar na elaboração de atualizações e revisão da legislação societária brasileira, à luz das novas tecnologias.

Palavras-Chave: Direito Societário e Mercado de Capitais / Governança Corporativa / Companhias Abertas e Companhias Fechadas / Tecnologia e Inovação / Assembleias Gerais / Estrutura Societária e Desempenho Econômico / Pedidos Públicos de Procuração / Voto e VI 
Participação a Distância / Blockchain e Smart Contracts / Direito Digital / Problemas de Agência / Absenteismo / Ativismo Societário 


\begin{abstract}
Over the past years, relevant developments in General Shareholders' Meetings and in the exercise of voting rights have taken place in Brazil and around the world. The adoption of remote voting systems and remote participation in General Shareholders' Meetings is ever more frequent, as well as the use of technology to improve public proxy solicitations and other aspects of General Shareholders' Meetings.

In this regard, the Brazilian Federal Law No. 6.404/76 was altered by the Brazilian Federal Law No. 12.431/2011, which promoted the inclusion of: (i) the sole paragraph article 121 of the Brazilian Federal Law No. 6.404/76, recognizing and legitimizing the possibility of remote voting and participation for shareholders in General Shareholders' Meetings in publiclyowned companies; and (ii) the sole paragraph of article 127 of Brazilian Federal Law No. 6.404/76, which establishes that shareholders who register their remote participation will be considered present at General Shareholders' Meetings. Additionally, several regulations and normative acts from CVM (Comissão de Valores Mobiliários - Brazilian Securities and Exchange Commission) have also been reviewed, notably - for example - CVM's Instruction No. 481/2009, as recently amended.

Some countries have even modernized the way General Shareholders' Meetings are held to allow virtual meetings, in which interactions between the conclave participants are exclusively remote.

However, we understand that the adoption of new technologies on General Shareholders' Meetings is welcome and must be done in such a way to expand horizons, and not to limit the exercise of rights. Notwithstanding, we are contrary to the reduction of the General Shareholders' Meetings to exclusively virtual (non-present) meetings where debates and discussions do not take place and/or in which there is limited interaction between presential and remote participants.

Traditionally, General Shareholders' Meetings play an important role as they enable shareholders to be involved and collectively monitor the company's activities, through 3 (three) special functions: $(i)$ Information Function: shareholders receive from the company information about relevant and different matters concerning the company; $(\underline{i i)}$ Forum Function: shareholders are offered a place to debate and pose questions regarding the company; and (iii) DecisionVIII
\end{abstract}


Making Function: shareholders gather together in order to collectively make decisions and determine the company's will. These 3 (three) functions have recently suffered important changes and undoubtedly need to be reconsidered in order to avoid the obsolescence of the Brazilian Corporate Law.

It is inconceivable to think that new technologies will not have any impacts on shareholders and management's relationship and/or on large companies' organizational structure. In face of such changes it is essential to study and comprehend classical institutes of Brazilian Corporate Law in view of the Fourth Industrial Revolution. In this sense, the analysis of the application of new technologies to General Shareholders' Meetings is innovative and extremely relevant to the legal community and to the capital markets, since it may bring shareholders closer and contribute to intensify shareholder activism and fight shareholders' absenteeism - changing corporate practices and, consequently, driving legislative and jurisprudential changes.

This paper aims to offer the following original contributions to legal studies: $(i)$ as a direct contribution: to analyze the effects exercised on General Shareholders' Meetings by the changes promoted on voting and remote participation mechanisms, as well as by changes on public proxy solicitations (in view of articles 121, sole paragraph, and 127, sole paragraph, of the Brazilian Federal Law No. 6.404/76 and the CVM Instruction No. 481/2009); and (ii) as an indirect contribution: to consider the potential effects of adopting new technologies and modern mechanisms on General Shareholders' Meetings, such as blockchains and smart contracts, in order to reduce the necessity of human activity in bureaucratic aspects of the meetings' procedures.

This paper will also analyze some systemic adaptations to be made in the corporate legislation, in order to suit it to the evolutionary standard and enable the adoption of technologies in Shareholders' General Meetings. The relevance of this paper lies in the collaboration to understand current trends and new ways of exercising shareholders' rights in publicly-owned companies, in order to (i) identify obsolescence in our current corporate law; and (ii) assist in the modernization and review of Brazilian corporate law, in light of new technologies. 
KEYwORDS: Corporate Law and Capital Markets / Corporate Governance / Publicly-Owned and Privately-Owned Corporations / Technology and Innovation / Shareholders' General Meetings / Corporate Structure and Economic Development / Public Proxy Solicitations / Remote Voting / Blockchain and Smart Contracts / Digital Law / Agency Problems / Absenteeism / Shareholders' Activism 


\section{RÉSUMÉ}

$\mathrm{Au}$ cours des dernières années, les Assemblées Générales des Actionnaires et l'exercice des droits de vote ont connu une évolution pertinente au Brésil et dans le monde. L'adoption de systèmes de vote et participation à distance aux Assemblées Générales est de plus en plus fréquente, ainsi que l'utilisation de la technologie pour améliorer les procédures de demande publique de procuration et d'autres aspects des Assemblées Générales.

Dans ce contexte, la loi fédérale brésilienne $n^{\circ}$ 6.404/76 a été modifiée par la loi fédérale brésilienne $\mathrm{n}^{\circ} 12.431 / 2011$, de sorte à inclure: (i) l'alinéa unique de l'article 121 de la loi fédérale brésilienne $\mathrm{n}^{\circ} 6.404 / 76$, qui reconnaît et légitime, dans les sociétés cotée, la possibilité du vote et de participation à distance des actionnaires aux Assemblées Générales; et (ii) l'alinéa unique de l'article 127 de la loi fédérale brésilienne $n^{\circ} 6.404 / 76$, qui considère présent à l'Assemblée Générale, l'actionnaire qui confirme sa présence à distance. Plus, nombreux règlements et actes normatifs de la CVM (Commission Brésilienne des Valeurs Mobilières et des Changes) ont également été examinés, notamment, l'Instruction n ${ }^{\circ} 481 / 2009$ de la CVM, que a été récemment modifiée.

Certains pays ont même modernisé la façon comment les Assemblées Générales sont organisées, afin d'accepter conclaves non présentiels, dans lesquels les interactions entre les participants du conclave se font exclusivement à distance.

Nous comprenons que l'adoption des technologies lors des Assemblées Générales est bienvenue et doit être faite comme un moyen d'élargir les horizons, et non comme une limite à l'exercice des droits. Nonobstant, nous sommes opposés à la réduction des Assemblées Générales à des réunions exclusivement virtuelles (non présentiels), sans débat, sans discussion et/ou avec des limitations d'interaction entre les participants qui participent à distance avec ceux qui sont effectivement présents au conclave.

Traditionnellement, les Assemblées Générales jouent un rôle important parce qu'elles permettent aux actionnaires de surveiller collectivement les activités de la société, à travers de trois (3) fonctions en spéciale: $\underline{\text { i })}$ Fonction d'Information: les actionnaires reçoivent de l'entreprise des informations sur des questions pertinentes concernant l'entreprise; (ii) Fonction du Forum: les actionnaires se voient offrir un lieu de débat et de formulation des questions concernant l'entreprise; et (iii) Fonction de Prise de Décision: les actionnaires se 
réunissent afin de prendre collectivement des décisions et de stipuler la volonté de l'entreprise. Ces trois (3) fonctions ont récemment subi d'importants changements et doivent sans aucun doute être réexaminées, afin d'éviter l'obsolescence du Droit des Sociétés Brésilien.

Il est inconcevable de penser que les nouvelles technologies n'auront aucun impact sur les relations entre les actionnaires, les administrateurs et/ou la structure organisationnelle des grandes l'e. Face à de tels changements, il est essentiel d'étudier et de comprendre les instituts classiques du droit des sociétés brésilien dans la perspective de la 4ème révolution industrielle. En ce sens, l'analyse de l'application des nouvelles technologies aux Assemblées Générales des actionnaires est novatrice et extrêmement pertinente pour la communauté juridique et les marchés des capitaux, parce que les progrès technologique peuvent rapprocher les actionnaires et contribuer à intensifier leur activisme et à lutter contre leur absentéisme - de mode a changer les pratiques des entreprises et, par conséquence, conduire des changements législatifs et jurisprudentiels.

Ainsi, cet article vise à offrir les suivantes contributions originales à la science juridique: (i) comme contribution directe - d'analyser les effets exercés sur les Assemblées Générales des actionnaires par les modifications apportées pour les mécanismes de vote et de participation à distance, ainsi que par les modifications des demandes publiques de procuration (en vue des articles 121, l'alinéa unique, et 127, l'alinéa unique de la loi fédérale brésilienne $\mathrm{n}^{\circ}$ 6.404/76, et de l'Instruction CVM n ${ }^{\circ}$ 481/2009); et ( ii) comme contribution indirecte - examiner les effets potentiels des technologies et des mécanismes modernes adoptés dans des Assemblées Générales d'Actionnaires, tels que les blockchains et les smart contracts, afin de réduire la nécessité d'activités humaines dans les aspects bureaucratiques des réunions.

Ce travail analysera également certaines adaptations systémiques à apporter à la législation des sociétés, afin de l'adapter à la norme évolutive et de permettre l'adoption de technologies dans les Assemblées Générales. La pertinence du présent travail réside dans sa collaboration pour comprendre les tendances actuelles et les nouveaux modes d'exercice des droits des actionnaires dans les entreprises publiques, afin (i) d'identifier l'obsolescence du droit des sociétés actuel; et (ii) aider à mise à jour et à faire la révision du droit brésilien des sociétés, en considérant des nouvelles technologies. 
MoTS-CLES: Droit des Sociétés et Marchés des Capitaux / Gouvernance des Sociétés / Société Cotée et Société Privée / Technologies et Innovation / Assemblées Générales / Structure de la Société et Développement Économique / Demande Publique de Procuration / Vote à Distance / Blockchain et Smart Contracts / Droit Digital / Problèmes d'agence / Absentéisme / Activisme d'Entreprise 


\section{ABREVIATURAS}

Audiência Pública SDM n ${ }^{\circ}$ Audiência Pública SDM nº 09/2014, com Relatório da $09 / 2014$ Diretora Luciana Dias, datado de 07 de abril de 2015

B3 B3 S.A. - Brasil, Bolsa, Balcão (atual denominação da BM\&F-Bovespa S.A. - Bolsa de Valores, Mercadorias e Futuros)

BVD Boletim de Voto a Distância

CEE Comunidade Econômica Europeia

CICORP Central de Inteligência Corporativa da B3

$\mathrm{COB}$

Commission des Opérations de Bourse (França)

Código Civil

Lei $\mathrm{n}^{\circ} 10.406$, de 10 de janeiro de 2002

Código Penal

Decreto-Lei $\mathrm{n}^{\circ}$ 2.848, de 7 de dezembro de 1940

CONSOB

Commissione Nazionale per le Società e la Borsa (Itália)

Constituição Federal

Constituição da República Federativa do Brasil, de 5 de outubro de 1988

CMVM

Comissão do Mercado de Valores Mobiliários (Portugal)

CVM Comissão de Valores Mobiliários (Brasil)

Diretiva UE no 2004/109/CE Diretiva do Parlamento Europeu e da CEE nº 109, de 15 de dezembro de 2004

Diretiva UE n 2007/36/CE Diretiva do Parlamento Europeu e da CEE nº 36, de 11 de julho de 2007

Diretiva UE nº 2016/679/CE Diretiva do Parlamento Europeu e da CEE nº 679, de 27 de abril de 2016

Diretiva UE nº 2017/828/CE Diretiva do Parlamento Europeu e da CEE nº 828, de 17 de maio de 2017

DLTs Distributed Ledger Technologies

DR Depositary Receipts

EDV Electronic Direct Voting

EPV Electronic Proxy Voting

EUA Estados Unidos da América

Exposição de Motivos n ${ }^{\circ}$ Exposição de Motivos no 196, de 24 de junho de 1976, do XIV 
196/1976

FrCC

IBGC

IBOVESPA

IBrX-50

IBrX-100

Instrução CVM no 165/1991

Instrução CVM no 168/1991

Instrução CVM no 319/1999

Instrução CVM no 323/2000

Instrução CVM no 324/2000

Instrução CVM no 358/2002

Instrução CVM no 361/2002

Instrução CVM no 400/2003

Instrução CVM no 481/2009

Instrução CVM no 487/2010

Instrução CVM no 552/2014

Instrução CVM no 561/2015

Instrução CVM no 565/2015

Instrução CVM nº 567/2015

Instrução CVM no 570/2015

Instrução CVM no 594/2017

Lei ${ }^{\circ} 8.078 / 1990$

Lei $n^{\circ} 8.666 / 1993$

Lei $n^{\circ} 8.934 / 1994$
Ministério da Fazenda

Code de Commerce (França)

Instituto de Brasileiro de Governança Corporativa

Índice da Bolsa de Valores de São Paulo, que corresponde ao indicador do desempenho médio das cotações das ações negociadas na B3

Índice Brasil, que corresponde ao indicador que avalia o retorno de carteira teoricamente composta pelas 50 (cinquenta) ações mais negociadas na B3

Índice Brasil, que corresponde ao indicador que avalia o retorno de carteira teoricamente composta pelas 100 (cem) ações mais negociadas na B3

Instrução CVM nº 165, de 11 de dezembro de 1991

Instrução CVM nº 168, de 23 de dezembro de 1991

Instrução CVM nº 319, de 3 de dezembro de 1999

Instrução CVM n ${ }^{\circ} 323$, de 14 de janeiro de 2000

Instrução CVM nº 324, de 19 de janeiro 2000

Instrução CVM nº 358, de 3 de janeiro de 2002

Instrução CVM n 361, de 5 de março de 2002

Instrução CVM n 400, de 29 de dezembro de 2003

Instrução CVM n 481, de 17 de dezembro de 2009

Instrução CVM nº 487, de 25 de novembro de 2010

Instrução CVM no 552, de 09 de outubro de 2014

Instrução CVM n ${ }^{\circ}$ 561, de 07 de abril de 2015

Instrução CVM no 565, de 15 de junho de 2015

Instrução CVM nº 567, de 17 de setembro de 2015

Instrução CVM no 570 , de 18 de novembro de 2015

Instrução CVM no 594, de 20 de dezembro de 2017

Lei ${ }^{\circ}$ 8.078/1990, de 11 de setembro de 1990

Lei $\mathrm{n}^{\circ}$ 8.666, de 21 de junho de 1993

Lei ${ }^{\circ}$ 8.934, de 18 de novembro de 1994 
Lei $n^{\circ} 8.987 / 1995$

Lei ${ }^{\circ} 9.784 / 1999$

Lei $\mathrm{n}^{\circ} 10.303 / 2001$

Lei $\mathrm{n}^{\circ} 12.431 / 2011$

LGPD

Lei $\mathrm{n}^{\circ} 13.818 / 2019$

Lei $\mathrm{n}^{\mathrm{o}} 13.874 / 2019$

LSA

LSC

MBCA

MP n ${ }^{\circ} 2.200 / 2001$
Lei $\mathrm{n}^{\mathrm{o}} \quad 13.709 / 2018$ ou

Lei $\mathrm{n}^{\circ} 8.987$, de 13 de fevereiro de 1995

Lei n ${ }^{\circ}$ 9.784, de 29 de janeiro de 1999

Lei $\mathrm{n}^{\circ} 10.303$, de 31 de outubro de 2001

Lei $\mathrm{n}^{\circ} 12.431$, de 24 de junho de 2011

Lei $n^{\circ}$ 13.709/2018, de 14 de agosto de 2018 (Lei Geral de Proteção de Dados)

Lei $\mathrm{n}^{\mathrm{o}} 13.818$, de 24 de abril de 2019

Lei $\mathrm{n}^{\circ} 13.874$, de 20 de setembro de 2019

Lei $\mathrm{n}^{\circ}$ 6.404, de 15 de dezembro de 1976

Ley de Sociedades de Capital (Espanha)

Model Business Corporation Act (EUA)

Medida Provisória $n^{\circ} 2.200$, de 28 de junho de 2001 (revisada e reeditada, posteriormente, pela Medida Provisória $n^{\circ}$ 2.200-1, de 27 de Julho de 2001, e pela Medida Provisória no 2.200-2, de 24 de Agosto de 2001)

MP nº 881/2019 ou MP da Medida Provisória no 881/2019, de 30 de abril de 2019, Liberdade Econômica convertida na Lei ${ }^{\circ} 13.874$, de 20 de setembro de 2019

MP n ${ }^{\circ} 892 / 2019$

NYSE Medida Provisória no 892/2019, de 05 de agosto de 2019 New York Stock Exchange (EUA)

OCDE Organização para a Cooperação e Desenvolvimento Econômico

OfícioCircular/CVM/SEP/N Ofício-Circular/CVM/SEP/No 3 , de 28 de fevereiro de ${ }^{\circ} 03 / 2019$ 2019

Portaria $n^{\circ} 529 / 2019$

Portaria ${ }^{\circ}$ 529, de 26 de setembro de 2019

$\mathrm{PL} \mathrm{n}^{\circ} 2.097 / 2015$

Projeto de Lei $n^{\circ} 2.097$, apresentado em 25 de junho de 2015

PL n ${ }^{\circ} 10.736 / 2018$

Projeto de Lei $\mathrm{n}^{\circ}$ 10.736, apresentado em 14 de agosto de 2018

RDB

Revista de Direito Bancário e do Mercado de Capitais

RDM

RDSVM

Revista de Direito Mercantil, Industrial, Econômico e Financeiro

Revista de Direito das Sociedades e dos Valores 
Mobiliários

Reg FD

Regulation Fair Disclosure da SEC (EUA)

RMBCA

Revised Model Business Corporation Act (EUA)

SCA

SEC

Stock Corporation Act

Securities and Exchange Commission (EUA)

STJ

Superior Tribunal de Justiça

STF

Supremo Tribunal Federal

TUF

Testo Unico della Finanza (Itália)

UE

União Europeia

$\mathrm{WpHG}$

Gesetz Über den Wertpapierhandel (Alemanha)

WpÜG

Wertpapiererwerbs Und Übernahmegesetz (Alemanha) 


\section{SUMÁRIO}

RESUMO

ABSTRACT

RÉSUMÉ

1 INTRODUÇÃO 1

2 ASSEMBLEIAS DE S/A 19

2.1 Conceito e Natureza Jurídica $\quad 19$

2.2 Espécies de Assembleias Gerais $\quad 24$

2.3 Características da Assembleia Geral 25

2.3.1 Órgão Deliberativo e Colegiado 26

2.3.2 Debate, Expressão e Formação da Vontade Social 27

2.3.3 Órgão Social Supremo, Permanente e Interno 29

2.4 Convocação da Assembleia Geral 32

2.4.1 Competência $\quad 32$

2.4.2 Prazo de Antecedência 34

2.4.3 Forma de Convocação, Publicação e Disponibilização de Documentos 36

2.4.4 Outros Elementos da Convocação 44

2.5 Ordem do Dia 4

2.6 Instalação $\quad 49$

$\begin{array}{lll}\text { 2.6.1 Credenciamento } & 51\end{array}$

2.6.2 Legitimação para participar na Assembleia $\quad 53$

2.6.3 Representação do Acionista $\quad 54$

$\begin{array}{lll}2.7 & \text { Mesa } & 57\end{array}$

2.8 Deliberação $\quad \mathbf{5 9}$

$\begin{array}{lll}\text { 2.8.1 Conceito e Procedimento } & 60\end{array}$

2.8.2 Natureza da Deliberação $\quad 62$

$\begin{array}{lll}2.8 .3 & \text { Quórum de Deliberação } & 63\end{array}$

$\begin{array}{lll}2.8 .4 \text { Votação } & 66\end{array}$

2.9 Ata, Encerramento e Formalização da Assembleia Geral 73

3 ASSEMBLEIAS VIRTUAIS E NOVOS INSTRUMENTOS APLICÁVEIS ÀS ASSEMBLEIAS DE S/A $\quad 76$

3.1 A Importância da Modernização $\quad 76$

3.2 Formatações Modernas da Assembleia Geral $\mathbf{8 1}$

3.2.1 Assembleia Virtual (Remote Only Shareholder Meeting) 87

3.2.2 Assembleia com Votação e Participação Remota (Remote Shareholder

Participation) 91

3.3 Assembleias Virtuais $\quad 95$

3.3.1 Vantagens associadas às Assembleias Virtuais 96

3.3.2 Desvantagens associadas às Assembleias Virtuais 98 
3.4.1.1 Art. 121, parágrafo único, e Art. 127, parágrafo único, da LSA 103

$\begin{array}{lll}3.4 .1 .2 & \text { Instrução CVM no 481/2009 } & 108\end{array}$

3.4.1.2.1 Boletim de Voto a Distância 109

3.4.1.2.2 Eleição de Membros do Conselho de Administração 123

3.4.1.2.3 Eleição de Membros do Conselho Fiscal 129

3.4.1.2.4 Pedido de Inclusão de Propostas no BVD 133

3.4.1.2.5 Voto a Distância Exercido por Prestadores de Serviços 136

3.4.1.2.6 Voto a Distância Exercido Diretamente 141

3.4.1.2.7 Cômputo dos Votos na Assembleia Geral 142

3.4.1.2.8 Cronograma da Votação a Distância 146

$\begin{array}{ll}\text { 3.4.1.2.9 A Realidade Brasileira } & 148\end{array}$

3.4.1.2.9.1 Pesquisa Empírica da B3 150

3.4.1.2.9.2 Constatações resultantes da Pesquisa Empírica da B3 152

$\begin{array}{ll}\text { 3.4.2 Pedidos Públicos de Procuração } & 157\end{array}$

$\begin{array}{llr}3.4 .2 .1 & \text { Origem } & 158\end{array}$

$\begin{array}{llr}3.4 .2 .2 & \text { Proxy Fights } & 159\end{array}$

$\begin{array}{ll}\text { 3.4.2.3 Art. } 126, \S 2^{\circ} \text {, da LSA } & 161\end{array}$

3.4.2.4 Instrução CVM no 481/2009 162

3.4.2.4.1 Caracterização como Pedido "Público" de Procuração 163

3.4.2.4.2 Requisitos do Pedido Público de Procuração 164

3.4.2.4.3 Princípio do Tratamento Igualitário 166

3.4.2.4.4 Divulgação de Documentos e Informações 166

3.4.2.4.5 Pedido Público de Procuração pela Administração 167

3.4.2.4.6 Procurações Eletrônicas 169

3.4.2.4.7 Procurações Não Eletrônicas 170

4 NOVAS TECNOLOGIAS E DIREITO SOCIETÁRIO 172

4.1 As Transformações da Sociedade Moderna e o Direito Societário 172

4.2 Tecnologia de Registro Distribuído (Blockchain) 174

$\begin{array}{lll}\text { 4.2.1 Conceito e variáveis } & 174\end{array}$

$\begin{array}{lll}\text { 4.2.2 Blockchains Públicas ou Privadas } & 178\end{array}$

4.2.3 Aplicação da Blockchain às Assembleias Gerais 179

$\begin{array}{ll}\text { 4.2.4 Livros Societários } & 187\end{array}$

$\begin{array}{ll}\text { 4.2.5 Disponibilização de documentos } & 191\end{array}$

4.3 Contratos Inteligentes (Smart Contracts) 193

4.3.1 Aplicação dos Smart Contracts às Assembleias Gerais 197

5 GOVERNANÇA CORPORATIVA

5.1 Problemas de Agência $\quad 201$

5.1.1 Acionistas Controladores vs. Acionistas Minoritários 205

$\begin{array}{ll}\text { 5.1.2 Acionistas vs. Administradores } & 208\end{array}$

5.1.3 Agentes Internos vs. Agentes Externos (Stakeholders) 213 
$\begin{array}{lll}5.2 & \text { Absenteísmo Societário } & 216\end{array}$

$\begin{array}{lll}\text { 5.2.1 Apatia Racional } & 219\end{array}$

5.2.2 Concentração Acionária: Baixo Impacto dos Minoritários 220

5.2.3 Custos de Participação nas Assembleias Gerais 221

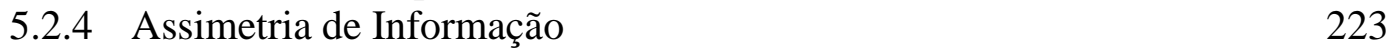

$\begin{array}{lll}\text { 5.2.5 Comportamento Carona } & 223\end{array}$

5.2.6 Pluralidade de Investimentos 224

$\begin{array}{lll}5.3 & \text { Ativismo Societário } & \mathbf{2 2 5}\end{array}$

$\begin{array}{lll}\text { 5.3.1 Estratégias de Ativismo Societário } & 227\end{array}$

5.3.2 Efeitos Positivos do Ativismo Societário 230

5.3.3 Efeitos Negativos do Ativismo Societário 231

5.4 Poderes vs. Proteções: Estrutura de Freios e Contrapesos 233

6 COMPARAÇÃO JURÍDICA: A EXPERIÊNCIA ESTRANGEIRA 237

6.1 Estados Unidos da América 238

$\begin{array}{lll}\text { 6.2 Europa } & \mathbf{2 4 5}\end{array}$

$\begin{array}{lll}6.2 .1 & \text { Reino Unido } 250\end{array}$

$\begin{array}{lll}6.2 .2 & \text { Portugal } & 252\end{array}$

$\begin{array}{lll}6.2 .3 & \text { Espanha } & 257\end{array}$

$\begin{array}{lll}6.2 .4 & \text { Itália } & 259\end{array}$

$\begin{array}{lll}6.2 .5 & \text { França } & 262\end{array}$

6.2.6 Alemanha 266

$\begin{array}{lll}6.2 .7 \text { Holanda } & 269\end{array}$

7 CONCLUSÃO $\quad 271$

BIBLIOGRAFIA $\quad 277$

Decisões Judiciais Nacionais $\quad 293$

Decisões Judiciais Estrangeiras $\quad 293$ 


\section{INTRODUÇÃO}

Este estudo pretende analisar os reflexos que as novas tecnologias têm apresentado e, conforme o caso, podem vir a apresentar em relação às Assembleias Gerais de sociedades anônimas.

A análise pretendida será realizada com olhar atento à realidade brasileira e buscará observar o tratamento da matéria no direito estrangeiro, buscando possíveis inspirações para soluções pátrias para o assunto. Na medida em que for aplicável, serão feitas distinções sobre especificidades inerentes às companhias abertas e às fechadas.

No Brasil e no mundo de forma geral, recentemente, têm-se observado relevantes transformações no regime jurídico das Assembleias Gerais e do exercício do direito de voto. São cada vez mais frequentes a adoção de sistemas de votação e participação a distância, bem como a utilização de elementos de tecnologia para aperfeiçoar os pedidos públicos de procuração e outros aspectos formais dos procedimentos assembleares.

O mundo está vivendo a Quarta Revolução Industrial ${ }^{1}$, em que tecnologias e inovações vêm sendo empregadas para automação de processos, promovendo convergência de tecnologias digitais, físicas e biológicas. Como consequência, a ordem econômica mundial vem sofrendo substanciais mudanças.

Com as tecnologias e, diante dos conhecidos efeitos da rede mundial de computadores (internet), as informações de modo geral estão cada vez mais acessíveis, de forma ampla e quase instantânea, ainda que em alguns casos sem validação de veracidade, completude e/ou adequação dos conteúdos.

Estamos no período histórico em que as informações são abundantes ${ }^{2}$ e as empresas de tecnologia se multiplicam e se utilizam de plataformas modernas capazes de promover

\footnotetext{
${ }^{1}$ SCHWAB, Klaus. A Quarta Revolução Industrial. Trad. Daniel Moreira Miranda. São Paulo: Edipro, 2016.

2 Nos últimos anos, houve uma profunda reformulação na maneira como as informações são produzidas, disseminadas e processadas, dando origem ao fenômeno do excesso de informação (information overload), em que dados relevantes e qualitativos se perdem em meio a grande quantidade de informações de menor relevância e qualidade, recomendando-se, inclusive, uma triagem e seleção sobre a veracidade e confiabilidade de algumas informações disponíveis, a fim de evitar notícias falsas (fake news).
} 
ruptura em relação à ordem econômica vigente, com redução de custos (financeiros e temporais) e mudança na forma de organização das relações no mundo dos negócios.

É inconcebível pensar que os avanços tecnológicos não produzirão reflexos nas relações entre acionistas, administradores e/ou na dinâmica organizacional das grandes companhias $^{3}$. Diante dessas mudanças, tornam-se essenciais estudos dedicados à compreensão de institutos clássicos do direito societário brasileiro, a partir do cenário da Quarta Revolução Industrial.

A análise sobre aplicação das tecnologias às Assembleias Gerais de sociedades anônimas é inovadora e de extrema relevância para a comunidade jurídica, pois auxiliará o entendimento acerca da adequação destas novidades a institutos jurídicos clássicos.

O desenvolvimento tecnológico promove encurtamento de distâncias entre acionistas, podendo colaborar para a intensificação do ativismo societário ${ }^{4}$ e contribuir para o combate ao absenteísmo ${ }^{5}$, com efeitos importantes no aperfeiçoamento das relações entre os diversos agentes das sociedades anônimas.

Com a evolução tecnológica, tornou-se possível a participação ao vivo de acionistas em Assembleias Gerais de companhias, independentemente da localidade em que estejam acontecendo. Alternativamente, na hipótese de não estarem participando ao vivo, as tecnologias propiciam mecanismos para a interação entre os ambientes virtual e presencial, inclusive, conforme o caso, por sistemas de votação e participação a distância.

\footnotetext{
${ }^{3}$ As mudanças nas formas de negócios e a valorização de bens intangíveis são tendências que precedem as plataformas tecnológicas. A importância de adaptar o estudo de institutos jurídicos sob novas perspectivas foi revelada por Charles Reich, ainda em 1964, no sentido de que: “(...) more and more of our wealth take the forms of rights or status rather than of tangible goods. (...) the automobile dealer's chief wealth is his franchise from the manufacturer which gives him exclusive sales rights within a certain territory, for it is his guarantee of income. His building, his stock of cars, his organization, and his goodwill may all be less valuable than his franchise. Franchises represent the principal asset of many business agreements, and organization may be the most valuable assets. The steel company`s relationships with coal and iron producers and automobile manufactures and construction companies may be worth more than all its plants and equipment." (REICH, Charles A. "The New Property". In: The Yale Law Journal, vol. 73, n. 5, abril de 1964, pp. 733-787).

${ }^{4} \mathrm{O}$ ativismo societário pode ser entendido como a atuação de acionistas minoritários na defesa de seus direito e interesses, usualmente realizada por meio de atuação conjunta e coordenada de determinado grupo destes acionistas. Em sentido semelhante, veja-se: MOURA AZEVEDO, Luís André N. de. "Ativismo dos Investidores Institucionais e Poder de Controle nas Companhias Abertas da Capital Pulverizado Brasileiras" In: MONTEIRO DE CASTRO, Rodrigo R.; MOURA AZEVEDO, Luís André N. de (coord.) Poder de Controle e Outros Temas de Direito Societário e Mercado de Capitais, pp. 218-262. São Paulo: Quartier Latin, 2010, p. 218.

${ }^{5} \mathrm{O}$ absenteísmo societário pode ser entendido como a abstenção do exercício do direito de voto, a partir de ausência previamente decidida e de maneira habitual nas Assembleias Gerais.
} 
De modo a buscar compreender a situação presente e ponderar sobre as perspectivas futuras das Assembleias Gerais, no que tange aos reflexos que as tecnologias têm apresentado e podem vir a apresentar no regime jurídico assemblear, é fundamental conhecer o tema desde a sua origem.

As Assembleias Gerais desempenham diversas funções em sociedades anônimas e têm enorme importância no Direito Societário. A “Assembleia Geral é o órgão social formado pelo conjunto de acionistas reunidos, devidamente convocado e instalado na forma da lei e dos estatutos, para deliberar sobre matéria de interesse da sociedade"6.

Não são todas as reuniões de acionistas que se revestem do aspecto assemblear, mas tão somente aquelas que tenham sido devidamente convocadas, instaladas e realizadas com observância das formalidades legais e estatutárias aplicáveis. Essa é uma percepção que, embora óbvia, é relevante para diferenciar potenciais encontros de acionistas realizados por internet, aplicativo e/ou outras plataformas sem respeitar as solenidades necessárias.

A Assembleia Geral é órgão deliberativo, interno e de natureza permanente nas sociedades anônimas ${ }^{7}$, que ocupa papel supremo na estrutura hierárquica dos órgãos sociais, e por meio do qual os acionistas contribuem para a formação da vontade social. A participação dos acionistas em Assembleias Gerais é muitas vezes comparada com a dos integrantes do povo em democracias diretas ${ }^{8}$.

\footnotetext{
${ }^{6}$ LAMY FILHO, Alfredo; PEDREIRA, José Luiz Bulhões (coord.). Direito das Companhias. $2^{\mathrm{a}}$ ed., atual. e ref. Rio de Janeiro: Forense, 2017, p. 246.

${ }^{7}$ Observe-se, porém, no tocante ao sentido de permanência, que "A assembleia-geral, apesar de ter - na curiosa formulação de Messineo - uma incarnazione intermittente, possui, contudo, existência material efêmera: limitase ao espaço de tempo no qual os acionistas nela se reúnem, discutindo e deliberando. Fora desses momentos é um órgão quiescente, devendo ser convocada, na forma da lei (arts. 123, 124 e 294, I, da Lei 6.404/197615), para poder atuar, salvo na hipótese de assembleia 'totalitária', que dispensa as formalidades previstas em lei para a convocação (art. $124, \S 4^{\circ}$ ). Exaurida que seja, a assembleia retorna ao estado de quiescência, até a próxima convocação e constituição. Tem a assembleia, pois, incontestável realidade jurídica, embora seja privada de existência material permanente" (FRANÇA, Erasmo Valladão Azevedo e Novaes (Invalidade das Deliberações de Assembleia das S/A, $2^{\mathrm{a}}$ ed., São Paulo: Malheiros, 2017, p. 39). No mesmo sentido, Waldirio Bulgarelli: a assembleia é um órgão "momentâneo na sua afirmação concreta, embora permanente na sua conformação teórica (...)” (cf. BULGARELLI, Waldirio. “Deliberar não deliberar é deliberar?'. In: Questões de Direito Societário. São Paulo: RT, 1983, p. 89).

${ }^{8}$ Alfredo Lamy Filho destaca que “O conjunto dos acionistas é o 'povo' - fonte de todo poder, que se manifesta em assembleia, como numa democracia direta. A assembleia delibera sobre os assuntos mais importantes, fixa a orientação geral dos negócios da sociedade e designa os administradores, que não são representantes dos acionistas, porém órgãos da sociedade." (LAMY FILHO, Alfredo; PEDREIRA, José Luiz Bulhões (coord.). Direito Das Companhias. $2^{\mathrm{a}}$ ed., atual. e ref. Rio de Janeiro: Forense, 2017, p. 60).
} 
A participação nas deliberações assembleares e o exercício do direito de voto ${ }^{9}$ são as formas pelas quais os acionistas participam na formação da vontade social. Devido à importância do exercício do voto na formação da vontade social, Erasmo Valladão pondera que tal direito, para além de um direito subjetivo, constituiria um poder-função do acionista ${ }^{10}$.

A depender de como vierem a ser aplicadas as tecnologias às Assembleias Gerais e o efeito que tal aplicação venha a ter, pode-se ponderar sobre a ampliação da participação dos acionistas nos conclaves, fazendo com que o direito de voto seja utilizado de forma efetiva por acionistas de diferentes perfis. Em tal cenário, haveria mudança substancial no contexto atual em que, na prática, apenas os acionistas controladores efetivamente participam e/ou possuem incentivos para participar de Assembleias Gerais na maior parte das companhias.

Em essência, os dispositivos da legislação acionária foram concebidos visando a incentivar o exercício pelos acionistas dos direitos de que são titulares ${ }^{11}$. Essa configuração legal busca assegurar que todos os acionistas possam, de alguma forma, influenciar na formação da vontade social, que é determinada com base no princípio majoritário ${ }^{12}$.

\footnotetext{
${ }^{9}$ Nelson Eizirik destaca que " $O$ voto constitui a manifestação do direito conferido a cada indivíduo de participar da formação da vontade de determinado grupo. Tratando-se de uma pretensão juridicamente exigível diante dos demais componentes do grupo, o direito de voto é direito subjetivo, ou seja, decorre de uma situação tida como legítima para fundamentar a participação de alguém na formação da vontade coletiva." (EIZIRIK, Nelson. A Lei das S/A Comentada. Volume I - 2 ${ }^{\mathrm{a}}$ ed. Revista e Ampliada - Artigos 80 a 137. São Paulo: Quartier Latin, 2015, p. 174).

10 "Nessa perspectiva, torna-se difícil caracterizar o direito de voto como um verdadeiro direito subjetivo, por definição livre no seu exercício, na medida em que, votando, o acionista deve antepor ao seu interesse o interesse da companhia, embora este último, como interesse comum, também em certa medida lhe pertença" (FRANÇA, Erasmo Valladão Azevedo e Novaes. Conflito de Interesses nas Assembleias de S.A. $2^{\mathrm{a}}$ ed. São Paulo: Malheiros, 2014, p. 69).

${ }^{11}$ Essa não é a opinião de Modesto Carvalhosa, para quem a legislação brasileira consagra o absenteísmo: " $A$ Lei n. 6.404, de 1976, ao adotar o regime de cessão de voto e ao cercear o seu exercício através da forma e da classe, legalizou o fenômeno do absenteísmo dos acionistas nas assembleias gerais. Ao assim proceder, o legislador de 1976 acentuou a tendência não associativa do acionista moderno. A lei de 1976 deixou de ser educativa, portanto, no que diz respeito à reversão dessa tendência danosa de não participação dos acionistas na condução e na elaboração da política da companhia." (CARVALHOSA, Modesto. Comentários à Lei das Sociedades Anônimas. Vol. II - Artigos 75 a 137. $5^{\mathrm{a}}$ ed. São Paulo: Saraiva, 2011, p. 425).

${ }^{12}$ Marcelo von Adamek destaca que "embora o sócio sempre participe da formação da vontade coletiva (através do voto ou, pelo menos, da sua participação nos conclaves, com direito de voz), fica sujeito, nas sociedades onde prevalece o princípio majoritário, à decisão tomada pela maioria (de sócios ou sócios representando a maioria do capital social, conforme o caso): 'as deliberações tomadas de conformidade com a lei e o contrato social vinculam todos os sócios, ainda que ausentes ou dissidentes (CC, art. 1.072, §5)"' (ADAMEK, Marcelo Vieira Von. Abuso de Minoria em Direito Societário. São Paulo: Malheiros, 2014, pp. 46-47). E, complementa o autor: "entre nós vige o princípio majoritário, a formação da vontade coletiva não ocorre apenas pelo critério de cabeça (one man, one vote), e sim, no mais das vezes, dá-se em função da participação dos sócios no capital social (CC, arts. 1.010 e 1.071; e LSA, art. 110)" (ADAMEK, Marcelo Vieira Von. Abuso de Minoria em Direito Societário. São Paulo: Malheiros, 2014, p. 50).
} 
Otto von Gierke ensina que o princípio majoritário promove a consolidação da vontade geral de determinado grupo, conforme definida pela maioria de seus membros. Esse mecanismo decisório assume que a decisão tomada pela maioria dos votos corresponde a resultado vinculante para todos os membros do grupo, inclusive dissidentes, ausentes e vencidos na deliberação tomada ${ }^{13}$.

No mundo moderno, com a formação das grandes companhias (macroempresas) e da intensificação da organização de empresas mediante mecanismos jurídicos capazes de propiciar negócios estruturados em grande escala, são cada vez mais complexos a gestão social, o fluxo de informações e o confronto de ideias entre os acionistas. Neste compasso, proliferamse conflitos societários e problemas de agência (agency problems $)^{14}$.

A consolidação do modelo econômico capitalista, especialmente após a $2^{\text {a }}$ Guerra Mundial, a evolução dos mercados de capitais internacionais, o desenvolvimento das economias de mercado e, sobretudo, os avanços tecnológicos encurtaram distâncias e propiciaram mecanismos eficientes para que agentes de mercado localizados em regiões diferentes praticassem negócios entre $\mathrm{si}^{15}$.

Nesse contexto econômico com reconhecidos efeitos no mundo dos negócios, as sociedades requerem investimentos e aportes de recursos em volumes cada vez mais

\footnotetext{
13 “'Como decorrência da relação associativa, o membro, para garantir a união do todo, deve submissão ao resultado da votação, transformando, assim, a vontade da maioria em vontade de todos. (...) Dessa forma, a decisão somente ganha força se a minoria realmente seguir a maioria. Caso a minoria continue a insistir na sua posição, talvez cometa um ato ilícito punível, mas não se chega a nenhuma decisão válida na associação". (GIERKE, Otto von. "Da História do Princípio da Maioria". Traduzido por Nilson Lautenschlager Jr. In: RDM, São Paulo: Editora Malheiros, vol 166/167, ago. 2013-jul. 2014, p. 13).

14 "(...) an "agency problem" - in the most general sense of the term - arises whenever one party, termed the "principal", relies upon actions taken by another party, termed the "agent", which will affect the principal's welfare. The problem lies in motivating the agent to act in the principal's interest rather than simply in the agent's own interest." (ARMOUR, John, HANSMANN, Henry; e KRAAKMAN, Reinier. The Anatomy of Corporate Law: A Comparative and Functional Approach. $3^{\mathrm{a}}$ ed. Oxford: Oxford University Press, 2017, p. 29).

${ }^{15}$ Relatos históricos informam que, a partir da década de 1950 , com o término da $2^{\mathrm{a}}$ Guerra Mundial e o fortalecimento da economia nos EUA e na Inglaterra, os investidores financeiros, em geral, perceberam que havia certos riscos inerentes a determinados produtos e/ou setores de atuação na economia que poderiam ser reduzidos com a diversificação dos setores nos quais os investimentos são realizados. É neste contexto que se fortalece ainda mais o interesse pelo mercado de capitais e a dinamização da dispersão das estruturas de capital nas companhias abertas de países em elevado estágio de evolução do modelo capitalista, especialmente nos EUA e na Inglaterra. Nesse sentido, ver: MOORE, Andrew G.T. "The Birth of Unocal: A Brief History". In: Delaware Journal of Corporate Law. v. 31, n. 3, 2006, pp. 865-886. Disponível em: 〈http://ssrn.com/abstract=946018〉. Acesso em 05.11.2019.
} 
expressivos, ocorrendo o processo de concentração empresarial ${ }^{16}$, com número crescente de operações de compra e venda de participações societárias e ativos, fusões, incorporações, incorporação de ações e transferências de controle de companhias ${ }^{17}$. Há desenvolvimento e diversificação dos mecanismos de captação de recursos e as companhias assumem dimensões cada vez maiores.

As relações são fortemente influenciadas por características da Era Digital ${ }^{18}$, em que a internet e outras tecnologias estão promovendo transformações diversas no mundo e, inclusive, nas relações jurídicas. Diante de tais modificações, há desafios e oportunidades que estão promovendo importantes mutações no Direito Societário e no regime jurídico das Assembleias Gerais.

Sendo assim, esta tese pretende analisar de forma pioneira ${ }^{19}$ as Assembleias Gerais de sociedades anônimas realizadas com a utilização de tecnologias modernas e mecanismos virtuais $^{20}$.

\footnotetext{
${ }^{16}$ Sobre o tema, lecionam Alfredo Lamy Filho e José Luiz Bulhões Pedreira: "[E]sse processo de concentração foi naturalmente induzido por dois objetivos visados pelas organizações produtivas: diminuir a instabilidade a que estão sujeitas as empresas que vendem em mercados altamente competitivos e obter as vantagens propiciadas pela grande dimensão - redução dos custos unitários de produção, integração vertical da produção ou maior poder nos mercados, capacidade para planejar a longo prazo, segurança de financiamento da expansão através de reinvestimento de lucros, capacidade de investir em pesquisa tecnológica e no desenvolvimento de novos produtos, e maior poder nas relações com as comunidades locais e os governos nacionais" (LAMY FILHO, Alfredo; BULHÕES PEDREIRA, José Luiz. "Formação e desenvolvimento das sociedades por ações". In: LAMY FILHO, Alfredo et al. A Lei das S.A. Vol. 1, pp. 19-102. Rio de Janeiro: Renovar, 1997, p. 62). Reproduzindo e complementando estas ideias, os próprios autores expuseram que "[o] processo de concentração conduziu à formação, nos países mais desenvolvidos, de empresas de grande porte, cujas dimensões, como organizações sociais, somente podem ser comparadas com os Estados nacionais e suas subdivisões" (LAMY FILHO, Alfredo; PEDREIRA, José Luiz Bulhões (coord.). Direito das Companhias. $2^{\text {a }}$ ed., atual. e ref. Rio de Janeiro: Forense, 2017, p. 570).

${ }^{17}$ COMPARATO, Fábio Konder. Aspectos Jurídicos da Macroempresa. São Paulo: RT, 1970, pp. 1-10.

${ }^{18}$ A Era Digital (que também é conhecida como "Era Tecnológica" e/ou "Era da Informação") é o nome atribuído subsequentemente à "Era Industrial", mais especificamente após a década de 1980, como consequência da proliferação dos efeitos de invenções como o microprocessador, a rede mundial de computadores, a fibra ótica e o computador pessoal.

${ }^{19}$ Respeitando, porém, as raízes pátrias e buscando apoio nos ombros de gigantes autores clássicos do Direito Societário. Sem trocadilho, faz-se aqui menção à célebre frase atribuída a Isaac Newtow: "Se vi mais longe foi por estar sobre os ombros de gigantes", que é frequentemente reproduzida em inglês: "If I have seen further it is by standing on the shoulders of giants".

${ }^{20}$ A palavra virtual é aplicada no sentido de emular e/ou replicar por meio digital a assembleia de acionistas, tal como tradicionalmente realizada. Neste sentido, o Dicionário Aurélio: "[Do lat. escolástico virtuale] Adj. $2 \mathrm{~g} .1$. Que existe como faculdade, porém sem exercício ou efeito atual. 2. Suscetível de se realizar; potencial. 3. Filos. Diz-se do que está predeterminado e contém todas as condições essenciais à sua realização. [Opõe-se, nesta acepção, a potencial (3) e atual (4).] 4. Inform. Que resulta de, ou constitui uma emulação, por programas de
} 
Alguns elementos já estão presentes na realidade atual ${ }^{21}$, porém com carência de um estudo nacional específico sobre o tema, voltado para a análise sobre os reflexos - positivos e/ou negativos - do emprego das tecnologias nas Assembleias Gerais de acionistas. Tal ausência vem concedendo espaço para estrangeirismos e tentativas de aplicação no Brasil de fenômenos havidos em outros países, sem as necessárias adaptações à nossa realidade e às características do nosso regime jurídico.

A realização de Assembleias Gerais, seja pela forma virtual ou com a adoção de outros elementos de tecnologia, é uma tendência mundial. No Brasil, tal propensão já começa a se concretizar.

Dentre as primeiras aparições de discussões formais sobre o tema da aplicação de tecnologias às Assembleias Gerais das companhias no Brasil, destaca-se inicialmente a consulta formulada pela MZ Consult Serviços e Negócios Ltda. à Superintendência de Relações com Empresas - SEP da CVM, que deu origem ao Processo Administrativo CVM RJ nº 2008/1794.

A questão foi examinada em Reunião do Colegiado da CVM realizada em 24 de junho de $2008^{22}$, na qual se admitiu a possibilidade de utilização de procurações de voto em

computador, de determinado objeto físico ou equipamento, de um dispositivo ou recurso, ou de certos efeitos ou comportamentos seus $\sim$ V. imagem - e trabalho." (grifo nosso) (FERREIRA, Aurélio Buarque de Holanda. Novo Aurélio do Século XXI: O Dicionário da Língua Portuguesa. $1^{\text {a }}$ ed. Rio de Janeiro: Nova Fronteira, 1999). Há quem pondere que a terminologia digital seria mais adequada. Neste sentido, o Dicionário Aurélio: "[Do lat. digitale.] Adj. 2 g. 1. Dos, ou pertencente ou relativo aos dedos: impressão digital. 2. Relativo a dígitos. 3. Inform. Que tem intervalos discretos, i.e. em que há um número finito de valores possíveis entre dois valores quaisquer. 4. Inform. Que é representado exclusivamente por números (segundo um código convencionado) e, portanto, passivel de processamento por computadores digitais: imagem digital; som digital; 5. Eletrôn. Diz-se de aparelho ou circuito cujo funcionamento é baseado em microprocessador." (FERREIRA, Aurélio Buarque de Holanda. Novo Aurélio do Século XXI: O Dicionário da Língua Portuguesa. $1^{\text {a }}$ ed. Rio de Janeiro: Nova Fronteira, 1999).

${ }^{21}$ As alternativas propostas pelas tecnologias devem solucionar problemas, em conformidade com as finalidades do Direito Societário brasileiro. Neste sentido, as formalidades legais que gravitam em torno das deliberações assembleares devem ser enxergadas sob a égide de um regime de anulabilidade, na forma concebida por Erasmo Valladão, para quem: "A disciplina geral de convocação e instalação das assembleias gerais acha-se estabelecida nos arts. 123 a 128 da Lei das S/A. A violação dessas disposições, portanto, ou de normas estatutárias que as complementam (v.g., art. 123, caput), acarreta a anulabilidade da assembleia geral, e, consequentemente de todas as suas deliberações. [...] Tem-se, assim, que a assembleia que se realizar com infringência das normas legais ou estatutárias de convocação ou instalação será, em princípio, anulável." (FRANÇA, Erasmo Valladão Azevedo e Novaes. Invalidade das deliberações de assembleia das $S / A$ e outros escritos sobre o tema da invalidade das deliberações sociais. $2^{\mathrm{a}}$ ed, rev. e aum. São Paulo: Malheiros, 2017, pp. 100-102).

${ }^{22}$ CVM. Processo Administrativo no RJ 2008/1794, Dir. Rel. Sergio Weguelin, j. em 24.06.2008. Disponível em: $\langle$ http://www.cvm.gov.br/export/sites/cvm/decisoes/anexos/0004/5973-0.pdf $>$. Acesso em 05.11.2019. 
forma digital nas Assembleias Gerais, com o propósito de ampliar a participação dos acionistas em tais eventos societários ${ }^{23}$.

Subsequentemente, a ideia foi aperfeiçoada em alterações promovidas pela Lei $\mathrm{n}^{\circ}$ 12.431/2011 na LSA, notadamente no que se refere às inclusões: $(\underline{i})$ do parágrafo único ao artigo 121 da LSA, a fim de reconhecer e legitimar, nas companhias abertas, a possibilidade de participação e voto a distância dos acionistas em Assembleia Geral; e (ii) do parágrafo único ao artigo 127 da LSA, que considera presente em Assembleia Geral, para todos os efeitos, o acionista que registrar a sua presença a distância.

É nessa direção que caminham a regulação e os atos normativos expedidos pela CVM, destacando-se, por exemplo, a Instrução CVM n ${ }^{\circ}$ 481/2009, com as alterações introduzidas pelas Instruções CVM n ${ }^{\circ}$ 552/2014, 561/2015, 565/2015, 567/2015 e 594/2017, que dispõem sobre informações, pedidos públicos de procuração ${ }^{24}$, participação e votação a distância em Assembleias Gerais.

No contexto da regulamentação da CVM sobre o parágrafo único do artigo 121 da LSA e o parágrafo único ao artigo 127 da LSA, conforme introduzidos pela Lei ${ }^{\circ}$ 12.431/2011, surgiram especulações diversas e ponderações sobre possíveis aplicações práticas de tais $\operatorname{dispositivos}^{25-26}$.

Diante do aumento das relações jurídicas realizadas eletronicamente, que em alguns setores e atividades chega a ser, atualmente, até predominante em relação às havidas por meio

\footnotetext{
${ }^{23}$ Posteriormente, como evolução e desdobramento do Processo Administrativo ${ }^{\circ}$ RJ 2008/1794, cite-se também a consulta formulada pela Assembleias Online Serviços e Informática Ltda. sobre a possibilidade de participação remota de cotistas em assembleias gerais de fundos de investimento, por meio de ferramenta eletrônica, que deu origem ao Processo Administrativo CVM n RJ 2010/12738, julgado na Reunião do Colegiado da CVM de 31.05.2011, que teve como Relator o à época Diretor Otavio Yazbek.

24 "Embora se trate de instrumento de grande utilidade em tese, o mercado acionário brasileiro ainda se encontra longe do estágio em que tal utilidade se poderia provar na prática. Por enquanto, a baixa dispersão acionária e o ativismo acionário ainda em formação fazem com que a proxy solicitation permaneça sendo uma peça subutilizada." (LAMY FILHO, Alfredo; PEDREIRA, José Luiz Bulhões (coord.). Direito das Companhias. 2a ed., atual. e ref. Rio de Janeiro: Forense, 2017, p. 315).

${ }^{25}$ YOKOI, Yuki. "Clicou, votou: seis questões sobre assembleias virtuais, que serão reguladas pela CVM este ano". In: Revista Capital Aberto no 101, jan. 2012.

${ }^{26}$ Em caminho de modernização, houve também o PL no 2.097/2015 sobre a realização, registro e publicidade de atos societários por meio eletrônico. O PL n 2.097/2015 será examinado em mais detalhes na Seção 3.2.1 e na Seção 3.4.1.1 deste trabalho.
} 
físico e presencial, tornaram-se cada vez mais necessários instrumentos para estabelecer segurança jurídica em tais relações.

O certificado digital é uma das ferramentas que vêm sendo utilizadas para garantir essa segurança, ao criar uma identidade virtual para aqueles que praticam negócios jurídicos na internet, garantindo a autenticidade necessária à representação das partes em tais negócios jurídicos. Em seu funcionamento, esse instrumento utiliza-se de chaves criptográficas que geram assinaturas e identificações eletrônicas, autênticas e individualizadas.

Dessa forma, é possível atribuir validade jurídica a determinados atos e/ou negócios jurídicos praticados virtualmente, a fim de reduzir e, na medida do possível, evitar fraudes, simulações e outros defeitos capazes de contaminar ato e/ou negócio jurídicos realizados virtualmente $\mathrm{e}^{27}$.

No exterior, há diversos exemplos de países que já usam tecnologias para participação e cômputo de votos em Assembleias Gerais, no compasso das modernizações viabilizadas pela Era Digital ${ }^{28}$.

Dentre as tecnologias, destaca-se o emprego do blockchain ${ }^{29}$, que pode ser descrita como uma espécie de livro-razão $\left(l e d g e r^{30}\right)$ capaz de registrar negócios entre partes, conhecidas

\footnotetext{
${ }^{27}$ Com a certificação digital, surgem também as figuras do: (i) e-CPF, que é uma espécie de identidade digital aplicável às pessoas físicas, que permite a estas realizarem operações virtuais, tal como se estivessem utilizando o CPF físico e tradicional; e (ii) do e-CNPJ, que é o certificado vinculado às pessoas jurídicas e emitido para uso pelos representantes legais das mesmas, que serve para a mesma finalidade de realização de operações virtuais, neste caso buscando mimetizar os efeitos do uso do CNPJ tradicional. O e-CPF e o e-CNPJ já servem para diversas finalidades e estão disponíveis para o uso do público em geral. O e-CPF vem sendo utilizado, por exemplo, por aqueles que precisa acessar o Sistema de Escrituração Digital das Obrigações Fiscais, Previdenciárias e Trabalhistas (eSocial), Empregador Doméstico e ou registrar a DIRPF - Declaração de Imposto de Renda de Pessoa Física, entre outros. O e-CNPJ vem sendo utilizado para acessar o Sistema de Escrituração Digital das Obrigações Fiscais, Previdenciárias e Trabalhistas (eSocial), Conectividade Social, emissão de Nota Fiscal Eletrônica - NF-e, Nota Fiscal Avulsa Eletrônica - NFA-e, Nota Fiscal Consumidor Eletrônica - NFC-e, Nota Fiscal de Serviço Eletrônica - NFS-e.

${ }^{28}$ LAFARRE, Anne; VAN DER ELST, Christoph. "Blockchain Technology for Corporate Governance and Shareholder Activism" (Março de 2018). In: European Corporate Governance Institute (ECGI) - Law Working Paper No. 390/2018. Disponível em:<https://ssrn.com/abstract=3135209>. Acesso em 05.11.2019.

${ }^{29}$ A plataforma online do dicionário Merriam-Webster define blockchain como "a digital database containing information (such as records of financial transactions) that can be simultaneously used and shared within a large decentralized, publicly accessible network; also: the technology used to create such a database. The technology at the heart of bitcoin and other virtual currencies, blockchain is an open, distributed ledger that can record transactions between two parties efficiently and in a verifiable and permanent way. (IANSTII, Marco e LAKHANI, Karim R. "Blockchain". In: Merriam-Webster.com. Disponível em: 〈https://www.merriamwebster.com/dictionary/blockchain>. Acesso em 05.11.2019).

${ }^{30}$ A tecnologia do blockchain é tão recente que a versão física do Black's Law Dictionary ainda não comporta
} 
e/ou desconhecidas, por mecanismos auditáveis, imutáveis e, consequentemente, considerados como confiáveis e seguros; utilizando rede descentralizada ponto-a-ponto (peer-to-peer network), que contabiliza todos os negócios havidos por meio de registros integrados mantidos pelos participantes vinculados à rede. Esse tipo específico de software pode anotar qualquer operação, com registros que são feitos em blocos e formam uma cadeia protegida por meio de criptografia, que está disponível para todos os usuários integrados à rede.

No Brasil e no mundo de forma geral, em suas aparições e empregos iniciais, a tecnologia blockchain esteve muitas vezes associada às criptomoedas ${ }^{31}$, mas há inúmeras outras aplicações possíveis para este sistema descentralizado de registro de informações e operações. Há, por exemplo, casos de utilização do blockchain para registros de nascimentos e óbitos, certidões de casamento, títulos de propriedade, diplomas escolares, procedimentos médicos, disponibilização de documentos e informações e, por último, sendo no caso o uso mais importante para esta tese, procedimentos de votação e reuniões em geral.

O blockchain e outras inovações tecnológicas já vêm sendo utilizados como ferramentas para aprimorar relações societárias, com efeitos positivos na governança corporativa $^{32}$. O emprego de tecnologias é capaz de melhorar a convergência entre acionistas controladores e minoritários; acionistas e administradores; agentes internos e stakeholders, reduzindo problemas de agência.

De acordo com Anne Lafarre e Christoph Van der Elst, em estudo seminal sobre o tema:

Blockchain is a technology that can offer smart solutions for classical corporate governance inefficiencies, especially in the relationship between shareholders and the company. Annual General Meetings (AGMs) are generally considered dull mandatory yearly rituals and its important

\footnotetext{
uma definição da expressão "blockchain". Entretanto, a fim de buscar subsídios em conteúdos correlatos, a expressão "Ledger" está assim definida: "1. A book or series of books used for recording financial transactions in the form of debits and credits; esp. a book in which a business or bank records how much money it receives and spends. - Also termed general ledger. 2. Archaic. A resident ambassador or agent - Also termed (in sense 2) leger, lieger." (GARNER, Bryan A (coord.). Black's Law Dictionary. 10a ed. Nova Iorque: Thompson Reuters, 2014).

${ }^{31}$ Dentre outras criptomoedas, citem-se BitCoin, LiteCoin, Cardano e Ethereum.

${ }^{32}$ Sobre o tema, referir-se, dentre outros a: (i) VERMEULEN, Erik P. M., Corporate Governance in a Networked Age (August 9, 2015). Wake Forest Law Review, 2015 Forthcoming; Lex Research Topics in Corporate Law \& Economics Working Paper No. 2015-4; Tilburg Law Research Paper No. 16/2015. Disponível em SSRN: https://ssrn.com/abstract=2641441. Acesso em 05.11.2019; e (ii) ZETZSCHE School, Dirk A., Corporate Governance in Cyberspace - a Blueprint for Virtual Shareholder Meetings (June 19, 2005). CBC-RPS No. 0011. Disponível em: SSRN: https://ssrn.com/abstract=747347. Acesso em 05.11.2019.
}

10 
theoretical functions, the information, forum and decision-making functions, are de facto eroded. In addition, the AGM suffers from procedural flaws, especially when shareholders vote remotely. ${ }^{33}$

A utilização de tecnologias em Assembleias Gerais de acionistas tende a produzir efeitos, positivos e negativos, a serem explorados adiante.

Dentre os efeitos positivos, que serão examinados em maiores detalhes nas próximas Seções deste trabalho, podemos apontar: $\underline{(i)}$ economia para as companhias em geral; (ii) melhoria da eficiência nas relações entre acionistas e a companhia, com potencial aumento da participação efetiva daqueles nas deliberações assembleares; (iii) combate ao absenteísmo (e, consequentemente, incentivo à interação entre os acionistas e as companhias); (iv) simplificação e aprimoramento do acesso a documentos e informações necessários ao adequado exercício do direito de voto; $\underline{(v)}$ facilitação do recebimento dos votos, das manifestações, protestos e documentos; e $\underline{(\mathrm{vi})}$ auxílio no credenciamento, na contagem dos votos e no anúncio dos resultados finais das votações.

Estas consequências positivas se inserem em meio a medidas coordenadas para incentivar a participação de acionistas minoritários e investidores em geral nas companhias, independentemente de possuírem relação direta com a administração e/ou com os acionistas que compõem o eixo decisório principal das companhias.

Entretanto, pondera-se também sobre diversos efeitos negativos que podem se materializar na utilização inadequada de tecnologias e com a supressão dos encontros presenciais, caso se admitam Assembleias Gerais realizadas totalmente a distância e/ou virtualmente. As Assembleias Gerais possuem papel fundamental para, dentre outros, o confronto de ideias, o debate, a proposição de alternativas e opções diferentes daquelas

\footnotetext{
${ }^{33}$ LAFARRE, Anne; VAN DER ELST, Christoph. "Blockchain Technology for Corporate Governance and Shareholder Activism" (Março de 2018). In: European Corporate Governance Institute (ECGI) - Law Working Paper No. 390/2018. Disponível em:<https://ssrn.com/abstract=3135209>. Acesso em 05.11.2019. Os mesmos autores têm inúmeros outros trabalhos sustentando que a tecnologia blockchain é capaz de resolver inúmeras ineficiências atuais e modernizar as Assembleias Gerais. Por exemplo: (i) LAFARRE, Anne; VAN DER ELST, Christoph. "Bringing the AGM to the 21st Century: Blockchain and Smart Contracting Tech for Shareholder Involvement (June 2017)". European Corporate Governance Institute (ECGI) - Law Working Paper No. 358/2017. Disponível em SSRN: or http://dx.doi.org/10.2139/ssrn.2992804. Acesso em 05.11.2019; e (ii) LAFARRE, Anne; VAN DER ELST, Christoph. Blockchain Technology for Modernizing the Shareholder Dialogue. Working Paper. Junho de 2018, p. 9, Disponível em: https://www.tilburguniversity.edu/upload/1413437f-2ccb-4fe9-bc0160aa0c7ec657_BlockchaintechnologyformodernizingshareholderdialogueWP.pdf. Acesso em 05.11.2019.
} 
inicialmente concebidas. No momento atual, não há ainda elementos tecnológicos que permitam que as Assembleias Virtuais desempenham eficientemente estes mesmos papéis ${ }^{34}$.

Nelson Eizirik avalia que:

O exercício do direito de voto não se dá unicamente pela manifestação monossilábica do 'sim' ou 'não', pois nele se compreendem: o ingresso e a presença na assembleia geral; a palavra; a proposição; o protesto; o pedido de informações à mesa ou à administração; a expressão do voto, verbalmente ou por escrito. ${ }^{35}$.

Reduzir as Assembleias Gerais a encontros não presenciais, sem debate, sem discussão e/ou com limitações de interação entre participantes seria uma ofensa ao Direito Societário. A adoção de tecnologias deve ser feita como uma forma de ampliação de horizontes e, não, uma limitação da extensão com que direitos podem ser exercidos.

Ressalte-se que é sempre importante ponderar sobre o contexto em que se inserem estas análises. De forma geral, inúmeras iniciativas no mundo vêm sendo direcionadas para incentivar a dispersão acionária, em oposição às companhias organizadas com concentração acionária.

A dispersão acionária é uma realidade restrita a poucas companhias abertas no Brasil. Durante o início do Século XXI, o mercado de capitais brasileiro apresentou significativo desenvolvimento, que foi acompanhado por aumento do número de companhias abertas com dispersão acionária.

No entanto, a despeito de todas as perspectivas de evolução e desenvolvimento do mercado de capitais brasileiro, há fortes razões históricas, econômicas e estruturais para se acreditar que o modelo prevalecente no Brasil tende a ser o das companhias com concentração acionária, registrando-se a presença de uma pequena (porém relevante) quantidade de companhias abertas com dispersão.

\footnotetext{
${ }^{34}$ Entretanto, em futuro breve, com a evolução tecnológica a tendência é que este cenário venha a mudar e, inclusive, a reflexão acima possa a vir ser revisitada.

${ }^{35}$ EIZIRIK, Nelson. A Lei das S/A Comentada. Volume II - 2a ed. Revista e Ampliada - Artigos 80 a 137. São Paulo: Quartier Latin, 2015, pp. 173-182.

12
} 
Sob a ótica econômica, são usuais as situações de exaltação da dispersão acionária em momentos de prosperidade e bonança, da mesma forma que são comuns os incentivos à concentração acionária nos contextos de crise, dificuldade e recessão ${ }^{36}$.

Há diversas iniciativas tendentes a ampliar a quantidade de companhias abertas organizadas com dispersão acionária em sua estrutura de capital no Brasil. Como exemplo, citem-se os esforços para manutenção de níveis mínimos obrigatórios de dispersão acionária (free float) em segmentos especiais instituídos pela $\mathrm{B} 3^{37}$.

Entender tal contexto é fundamental para compreender adequadamente a melhor forma de adaptação de políticas públicas relacionadas à modelagem das Assembleias Gerais a essa nova realidade das tecnologias, uma vez que - em companhias com cenário de dispersão acionária - muitos acionistas, notadamente aqueles com perfil de investidores ${ }^{38}$, não têm

\footnotetext{
${ }^{36}$ Erik Oioli afirma que " $n$ a empresa em que o poder empresarial é detido pelos administradores [hipóteses de alta dispersão acionária], a companhia continua a organizar juridicamente uma sociedade empresária, mas a análise econômica e social da empresa mostra que os titulares das ações deixam de desempenhar o papel de acionistas, pois não exercem de fato o comando dos administradores: salvo em momento de grave crise, não são, de fato, a fonte do poder empresarial, e se comportam como meros credores de dividendos [...] Portanto, o papel dos investidores institucionais e, de forma geral, dos titulares de blocos significativos de ações, como portadores da bandeira do ativismo pode ser limitado e não resolve, por si só, o problema do monitoramento dos administradores. Será útil, de forma geral, na gestão de crises ou mesmo como contraponto à atuação dos administradores nas OPA para aquisição de controle" (OIOLI, Erik Frederico. Regime Jurídico do Capital Disperso na Lei das S.A. São Paulo: Almedina, 2014, p. 233).

${ }^{37}$ Atual denominação da BM\&FBovespa, após a combinação com a CETIP

${ }^{38}$ Joseph de la Vega - escritor e empresário espanhol radicado na Holanda, que é autor da obra clássica Confusion de Confusiones, conhecida como o livro mais antigo sobre mercado de capitais - apontava desde 1688 a existência de 3 (três) tipos de acionista, com base nos seus respectivos perfis. Há o "acionista rendeiro", que é aquele que compra e detém as ações no intuito de receber dividendos; há o "acionista especulador", que está interessado na oscilação do valor das ações, a fim de obter ganho na compra ou na venda de ações, a depender da sua variação na bolsa; e há também o "acionista empreendedor", cuja motivação, embora também seja o lucro a partir do aumento do valor da ação, é participar ativamente da condução dos negócios sociais. Por estas razões associadas aos diferentes perfis de acionistas, diz-se que o acionista empreendedor tem maiores incentivos para engajar-se ativamente na vida da companhia, inclusive participando das deliberações assembleares. Nas palavras do autor: "Every year the financial lords and the big capitalists enjoy the dividends from the shares they have inherited or have bought with money of their own. They do not care about movements in the price of the stock. Since their interest lies not in the sale of the stock but in the revenues secured through the dividends, the higher value of the shares forms only an imaginary enjoyment for them [...]. The second class is formed by merchants who buy a share (of 500 pounds) and have it transferred in their name (because they are expecting favorable news from India or of a peace treaty in Europe). They sell these shares when their anticipations come true and when the price rises [...]. Gamblers and speculators belong to the third class. They have tried to decide all by themselves about the magnitude of their gains and, in order to do so, ... they have put up wheels of fortune" (DE LA VEGA, Joseph. Confusión de Confusiones. $1^{\text {a }}$ ed. New York: Marketplace Books, 1996).
} 
interesse ou disponibilidade para comparecer às Assembleias Gerais e/ou tomar parte nas deliberações assembleares ${ }^{39}$.

No âmbito da Audiência Pública SDM no 09/2014, a B3 destacou que o fenômeno do absenteísmo em todo o mundo decorre em grande medida dos baixos incentivos para fazer com que os acionistas incorram nos elevados custos de participação em Assembleias Gerais ${ }^{40}$.

O fenômeno do absenteísmo nas Assembleias Gerais tem sido considerado um problema a ser enfrentado pela legislação e por órgãos reguladores do mercado de capitais em diversos países. Neste trabalho analisaremos o tema e apresentaremos possíveis alternativas para mitigá-lo.

Há 3 (três) principais soluções normativas - que vêm sendo discutidas e, em alguns países, adotadas - para reduzir esse distanciamento entre investidores e as companhias: $\underline{(i)}$ as assembleias virtuais, em que os acionistas participam do conclave por meio da internet e/ou valendo-se de outros sistemas eletrônicos; $\underline{\text { ii) }}$ a representação do acionista por procurador, que poderá ocorrer em consequência de um pedido público de procuração; e (iii) a participação remota do acionista em Assembleias Gerais, de modo que este possa votar e participar mesmo que a distância.

Este trabalho buscará indagar sobre os impactos das tecnologias em cada um dos mecanismos, institutos e fenômenos típicos das Assembleias Gerais; desde as questões formais até as questões substanciais; dos preparativos até o conclave; da convocação e disponibilização de documentos e informações até a tomada das deliberações assembleares; da sugestão das deliberações até a divulgação final do mapa de votação analítico, com o resultado final das deliberações tomadas.

\footnotetext{
39 A título meramente exemplificativo, vejam-se os comentários de Alfredo Lamy Filho e José Luiz Bulhões Pedreira: "[os acionistas] exercem profissões ou têm outros negócios e aplicam em ações, como em qualquer outro tipo de investimento, para obter renda ou lucro, desde que não tenham que administrar os empreendimentos que geram esse lucro. Essa divisão nítida de subfunções empresariais, facilitada pelo modelo de companhia, explica a omissão do público investidor em comparecer às assembleias gerais para discutir e votar as decisões sobre o destino da companhia, a não ser quando sente que há perigo de perder seu investimento" (LAMY FILHO, Alfredo; PEDREIRA, José Luiz Bulhões (coord.). Direito das Companhias. $2^{\mathrm{a}}$ ed., atual. e ref. Rio de Janeiro: Forense, 2017, p. 182).

${ }^{40}$ CVM. Audiência Pública SDM no 09/2014. Relatório de Análise - Audiência Pública SDM no 09/2014 Processo Administrativo CVM no RJ 2011/13930, Dir. Rel. Luciana Dias, j. em 07.04.2015. Disponível em: <http://www.cvm.gov.br/export/sites/cvm/audiencias_publicas/ap_sdm/anexos/2014/sdm0914relatorio.pdf $>$. Acesso em 05.11.2019, p. 3. 14
} 
A expectativa é oferecer contribuições originais à ciência jurídica.

A contribuição imediata será analisar os reflexos nas Assembleias Gerais das mudanças promovidas pelos mecanismos de voto e participação a distância e, também, pelas modificações nos pedidos públicos de procuração, diante dos artigos 121, parágrafo único, e 127, parágrafo único, da LSA, conforme as alterações efetuadas pela Lei $n^{\circ} 12.431 / 2011$, e aquelas introduzidas na Instrução CVM no 481/2009 pelas Instruções CVM no 552/2014, $561 / 2015,565 / 2015,567 / 2015$ e 594/2017.

A contribuição mediata é recomendar a adoção de tecnologias e mecanismos modernos nas Assembleias Gerais, como blockchains e smart contracts, a fim de reduzir a necessidade de atuação humana em aspectos burocráticos do procedimento assemblear. Tal adoção pressuporia algumas adequações na legislação societária brasileira, notadamente substituindo os arcaicos livros societários das companhias por registros eletrônicos, incentivando que as ações de emissão das companhias sejam escriturais, especialmente se quisermos adotar tal política pública tanto em companhias abertas quanto em fechadas.

Para tanto, buscando construir raciocínio lógico e sequencial, inicialmente, analisaremos os aspectos clássicos das Assembleias Gerais em sociedades anônimas, com detalhamento de questões tradicionais e confrontando algumas mudanças recentes. O trabalho inicia pela raiz e pelas fundações do instituto jurídico. Examinaremos o conceito e a natureza jurídica da Assembleia Geral.

Abordaremos as características da Assembleia Geral, enquanto órgão social deliberativo, supremo, permanente e interno das companhias, com funções colegiadas e responsável pelo debate, expressão e formação da vontade social. Analisaremos regras e detalhes sobre a convocação da Assembleia Geral, inclusive, mas não apenas, poderes e competências, prazos de antecedência, forma de realização e outros elementos procedimentais relevantes.

Estudaremos também a importância da disponibilização de documentos e informações, inclusive aspectos relativos à definição da ordem do dia e outras questões diversas pertinentes à instalação das Assembleias Gerais, considerando detalhes sobre credenciamento de participantes, legitimação para participar e regras de representação de acionistas por procuradores e terceiros em geral. Analisaremos também aspectos importantes sobre a 
deliberação da sociedade anônima, inclusive examinando procedimentos, quórum de deliberação e questões atinentes ao debate e à votação.

Em seguida, estudaremos as Assembleias Virtuais e os novos instrumentos que vêm sendo aplicados às Assembleias Gerais, ponderando sobre a importância de tal modernização, uma vez que o instituto vem sofrendo inúmeras mudanças e influências recentes, que fazem com que o processo decisório se inicie muito antes do que o próprio encontro assemblear.

Abordaremos as formatações modernas da Assembleia Geral, com atenção à Assembleia Virtual (Remote Only Shareholder Meeting) e à Assembleia com Votação e Participação Remota (Remote Shareholder Participation). Faremos breve análise sobre as Assembleias Virtuais, que não são uma realidade presente no Brasil, mas que são muito comuns nos EUA e têm sido especuladas no Brasil e na Europa. Tal análise dissecará vantagens e desvantagens associadas às Assembleias Virtuais.

Desse modo, chegaremos a um dos pontos nucleares deste trabalho, que é o estudo sobre as Assembleias com Votação e Participação Remota, onde pretendemos fazer nossa contribuição original imediata ao Direito Societário. Neste ponto, será dedicado estudo sobre voto e participação a distância, analisando o art. 121, parágrafo único e o art. 127, parágrafo único, da LSA. Em seguida, exporemos pormenorizadamente a Instrução CVM nº 481/2009, examinando detalhes como o boletim de voto a distância, a eleição de membros do Conselho de Administração e do Conselho Fiscal. Em seguida, concluindo esta parte, analisaremos as transformações que o sistema de voto e participação a distância vem implementando em relação à visão clássica das Assembleias Gerais e, aqui, faremos uma análise sobre dados empíricos coletados pela Central de Inteligência Corporativa (CICORP) da B3 na experiência prática das Assembleias Gerais de companhias abertas no Brasil, nos anos de 2017, 2018 e 2019.

Em seguida, analisaremos os Pedidos Públicos de Procuração, que tiveram sua origem nas proxy fights dos EUA, mas que atualmente são também aplicáveis no Brasil e estão expressamente previstos no art. $126, \S 2^{\circ}$, da LSA. Exporemos as mudanças havidas na Instrução CVM n 481/2009 e alguns elementos de especial importância sobre o tema. Exporemos as características diversas dos Pedidos Públicos de Procuração, analisando, inclusive, alguns aspectos polêmicos sobre a admissibilidade de emprego de procurações eletrônicas e não eletrônicas neste contexto de convergências entre tecnologia e tradição. 
Ainda no cerne dos pontos em debate, examinaremos aplicações das novas tecnologias ao Direito Societário, com especial interesse nas transformações que já estão sendo provocadas na sociedade moderna. Abordaremos o blockchain, distinguindo as redes públicas e privadas, bem como a interessante e promissora possibilidade de aplicação desta tecnologia às Assembleias Gerais, buscando modernizar também outros aspectos formais do Direito Societário, como os registros de ações por livros societários e a disponibilização de documentos e informações referentes à companhia. Aqui realizaremos a nossa contribuição mediata à ciência jurídica. Em seguida, concluiremos com breve exame sobre os smart contracts e como eles podem ser aplicados às Assembleias Gerais.

Sequencialmente, abordaremos a governança corporativa, examinando os problemas de agência típicos das sociedades anônimas, quais sejam aqueles entre: $(i)$ acionistas controladores e minoritários; (ii) acionistas e administradores; e (iii) agentes internos e externos (stakeholders). Tal análise terá como objetivo examinar o fenômeno do absenteísmo societário e das motivações existentes em relação a tal comportamento, a fim de demonstrar a importância do ativismo societário e ponderar sobre potenciais estratégias utilizadas nesse sentido, examinando seus efeitos positivos e negativos, e demonstrando como exercem papel importante no sistema de poderes versus proteções, concebido na estrutura de freios e contrapesos nas sociedades anônimas.

Por fim, será realizada breve análise comparativa sobre a experiência estrangeira em relação à adoção de tecnologias nas Assembleias Gerais, com enfoque nos EUA e na Europa, notadamente Inglaterra, Portugal, Espanha, Itália, França, Alemanha e Holanda. O entendimento do panorama internacional é importante para situar o Brasil na matéria e aferir onde e em que medida fixaremos as nossas raízes. Serão feitas considerações sobre a utilização, no Brasil, de tecnologias e inovações nas Assembleias Gerais, com cuidados para que essa adoção seja realizada com base em parâmetros do nosso sistema jurídico, sem exagerados estrangeirismos e aplicações entre nós de técnicas que já se revelaram inadequadas no exterior.

A pretensão, ao final, é fornecer à comunidade jurídica fundamentos para entendimento sobre a utilização das tecnologias nas Assembleias Gerais, sempre analisando o tema do ponto de vista jurídico, sem nos aventurarmos em outras áreas do conhecimento como 
Engenharia, Programação Digital e Tecnologia da Informação, que não são escopo desta tese jurídica ${ }^{41}$.

${ }^{41}$ Para tal análise do funcionamento da tecnologia blockchain sob a ótica da Engenharia, da Programação Digital e da Tecnologia da Informação, ver: (i) ROSENFELD, Meni. "Analysis of hashrate-based double-spending" (Fevereiro de 2014). In: ArXiv no 1402.2009. Disponível em: 〈https://arxiv.org/abs/1402.2009〉. Acesso em 05.11.2019; (ii) MENEZES, Alfred J.; VANSTONE, Scott A.; OORSCHOT, Paul C. Van. Handbook of Applied Cryptography. $5^{a}$ ed. Boca Raton: CRC Press, Inc., 2001; e (iii) KHALIQUE, Aqeel; SINGH, Kuldip; SOOD, Sandeep. Implementation of Elliptic Curve Digital Signature Algorithm. In: International Journal Of Computer Applications. Roorkee, pp. 21-27. maio 2010. 


\section{CONCLUSÃO}

Cumprindo com a nossa proposta inicial, este trabalho analisou os atuais reflexos que as tecnologias já têm apresentado em relação às Assembleias Gerais de sociedades anônimas e, ainda, propôs algumas digressões em relação às perspectivas futuras sobre o tema.

A análise da aplicação das tecnologias às Assembleias Gerais é inovadora e de extrema relevância para a comunidade jurídica e para o mercado de capitais. O desenvolvimento tecnológico tem potencial para encurtar distâncias entre acionistas, colaborar para o ativismo societário e contribuir para o combate ao absenteísmo.

O absenteísmo nas Assembleias Gerais tem sido considerado um problema a ser enfrentado pela legislação e por órgãos reguladores do mercado de capitais em diversos países. A utilização de tecnologia tende a ser a forma mais eficiente para apresentar possíveis alternativas para mitigar o absenteísmo.

O estudo metodológico do tema, no Brasil e no mundo, revela a existência de soluções que vem sendo utilizadas como padrão para solucionar tal problema, quais sejam: (i) as Assembleias Virtuais (Remote Only Shareholder Meeting); e (ii) as Assembleias com Votação e Participação Remota (Remote Shareholder Participation).

As Assembleias Virtuais são polêmicas e, conforme exposto anteriormente, estão felizmente distantes da realidade brasileira. Todavia, as Assembleias Gerais com votação e participação remota já vêm ocorrendo entre nós, sem estudos específicos sobre o tema.

A LSA já autoriza que companhias abertas no Brasil promovam Assembleias Gerais em que os acionistas tenham a possibilidade de participar e votar a distância, conforme artigo 121, parágrafo único, e artigo 127, parágrafo único, da LSA.

A experiência prática das Assembleias Gerais de companhias abertas realizadas no Brasil nos anos de 2017, 2018 e 2019 já trouxe alguns ensinamentos iniciais, que inclusive serviram de amostragem para pesquisa empírica conduzida pela Central de Inteligência Corporativa (CICORP) da B3.

Os resultados de tal pesquisa em relação à aplicação prática do sistema de voto e participação a distância nas Assembleias Gerais no Brasil, em 2017, 2018 e 2019 apresentam algumas conclusões iniciais, comprovando que a ferramenta é capaz de aumentar o número de 
acionistas participantes e votantes em Assembleia Geral e, deste modo, reduzir o absenteísmo e gerar incentivos ao engajamento de acionistas no exercício do direito de voto e outros direitos políticos em sociedades anônimas.

Todavia, a comprovação do aumento da quantidade de votos exercidos ainda não está associada a incremento na qualidade como o voto é exercido. Espera-se que tal efeito esteja conexo à evolução das tecnologias empregadas para este propósito.

O caminho adotado pelos países da União Europeia em relação à adoção de tecnologias foi um pouco diferente daquele adotado pelos EUA. Há maior alinhamento no tratamento da matéria entre o Brasil e os países integrantes da União Europeia.

De forma geral, tanto no Brasil quanto na União Europeia o caminho da modernização vendo sendo trilhado pela admissibilidade de: $\underline{(i)}$ representação do acionista por procurador, que poderá ocorrer em consequência de um pedido público de procuração; e (ii) participação remota do acionista em Assembleias Gerais, de modo que este possa votar e participar mesmo que a distância.

As Diretiva UE n ${ }^{\circ}$ 2007/36/CE e da Diretiva UE n ${ }^{\circ}$ 2017/828 tiveram enorme influência no Brasil. A regulamentação da CVM sobre o parágrafo único do artigo 121 da LSA e o parágrafo único ao artigo 127 da LSA, conforme introduzidos pela Lei nº 12.431/2011, é comprovação dessa influência europeia.

Tais diretivas inegavelmente foram a grande inspiração no contexto da elaboração das Instruções CVM nº 552/2014, 561/2015, 565/2015, 567/2015 e 594/2017, que modificaram e aprimoraram a Instrução CVM n ${ }^{\circ}$ 481/2009, com regras de pedidos públicos de procuração, de participação e votação a distância em Assembleias Gerais das sociedades anônimas.

A expectativa em relação à aplicação de tecnologias às Assembleias Gerais é que estas gerem a ampliação da participação dos acionistas nos conclaves, fazendo com que o direito de voto venha a ser utilizado de forma mais efetiva por acionistas de diferentes perfis.

De forma geral, pretende-se incentivar o ativismo societário, combater o absenteísmo societário e evitar que as Assembleias Gerais sejam apenas frequentadas por acionistas controladores, que efetivamente participam e/ou possuem incentivos para participar de Assembleias Gerais. 
Entretanto, pondera-se também sobre diversos efeitos negativos que podem se materializar na utilização inadequada de tecnologias e com a supressão dos encontros presenciais, caso admitam-se Assembleias Gerais realizadas totalmente a distância e/ou virtualmente.

As Assembleias Gerais possuem papel fundamental para, dentre outros, o confronto de ideias, o debate, a proposição de alternativas e opções diferentes daquelas inicialmente concebidas. O exercício do direito de voto não se resume à manifestação monossilábica do 'sim' ou 'não'.

Reduzir as Assembleias Gerais a encontros não presenciais, sem debate, sem discussão e/ou com limitações de interação entre participantes presenciais e remotos seria uma ofensa ao Direito Societário. A adoção de tecnologias deve ser feita como uma forma de ampliação de horizontes e, não, uma limitação da extensão com que direitos podem ser exercidos.

Tivemos também algumas conclusões sobre os potenciais efeitos a serem obtidos com a adoção de tecnologias e mecanismos modernos nas Assembleias Gerais, como blockchains e smart contracts, a fim de reduzir a necessidade de atuação humana em aspectos burocráticos do procedimento assemblear.

Entendemos que a legislação societária precisará ser repensada em alguns pontos, até mesmo em consonância com a interpretação evolutiva, de modo a assegurar que o texto da lei esteja conciliável com a prática.

Em paralelo às atualizações feitas no artigo 121, parágrafo único, e no artigo 127, parágrafo único, da LSA, registre-se que foi incluído também o $\$ 2^{\circ}$ no art. 100 da LSA, prevendo que nas companhias abertas, os livros societários poderão ser substituídos por registros mecanizados ou eletrônicos, desde que observadas as normas expedidas pela CVM.

Todas estas adaptações legislativas se inserem no contexto de medidas coordenadas à atualização das Assembleias Gerais a realidade atual.

Como visão de política pública, a atual solução adotada é ainda muito tímida. As companhias abertas representam no Brasil apenas uma pequena fatia do total de sociedades anônimas regularmente registradas em nosso país, em que prevalecem como imensa maioria as companhias fechadas. 
Sendo assim, se efetivamente se buscasse promover modernização dos livros societários, minimamente deveria ser prevista alguma solução abrangendo as companhias fechadas.

Recomenda-se a introdução de $\S 3^{\circ}$ no art. 100 da LSA, autorizando que as companhias fechadas também substituam os livros societários por registros mecanizados ou eletrônicos, sendo que, no caso das companhias fechadas, caberia ao Poder Executivo regulamentar a matéria, tal como o faz a CVM em relação às companhias abertas.

Ainda não há no Brasil autorização legal para que os livros societários de companhias fechadas possam ser substituídos por registros mecanizados ou eletrônicos. Tal autorização legislativa é o passo fundamental para viabilizar o emprego de tecnologias como blockchains e smart contracts.

A tecnologia blockchain poderia ser utilizada como instrumento de registro de propriedade de ações, substituindo os arcaicos e obsoletos livros societários, simplificando e democratizando a divulgação de documentos e o fluxo de informações entre integrantes dessa cadeia e, a um só tempo, alcançando benefícios diferentes capazes de reposicionar o uso de ferramentas tradicionais do Direito Societário.

Consequentemente, a mesma tecnologia que serviria de plataforma para registro de propriedade de ações, permitiria aprimorar as relações existentes entre os acionistas e entre as companhias e os seus acionistas, com efeitos positivos na governança corporativa, inclusive reduzindo problemas de agência, fortalecendo o sistema de freios e contrapesos concebidos na legislação societária, mitigando riscos de conflitos e problemas de agência nas relações entre (i) acionistas controladores e minoritários; (ii) acionistas em geral e administradores; e (iii) agentes internos e agentes externos (stakeholders).

A blockchain poderia ser empregada para registrar os acionistas presentes nas Assembleias Gerais, contabilizando, portanto, a representatividade destes vis-à-vis o capital social da companhia, a fim de automatizar o cômputo do atingimento do quórum de instalação da Assembleia Geral. Em seguida, serve também como forma de, conciliando participantes presenciais e remotos, viabilizar o exercício do direito de voto inerente às ações que houverem sido relacionadas na blockchain e apurar o resultado das deliberações tomada, contabilizando atingimento de quórum de deliberação e satisfação de percentuais de participação acionária para 
exercício de determinados direitos especiais, inclusive eventuais proteções a minorias dotadas de participações relevantes.

A mesma tecnologia blockchain empregada para a Assembleia Geral (e exercício de direitos políticos inerentes as ações) pode auxiliar a aperfeiçoar relações entre acionistas, entre estes e administradores e de todos estes com a própria companhia.

É possível afirmar que os mecanismos de votação e participação a distância já se comprovaram capazes de aumentar o número de acionistas participantes e votantes em Assembleia Geral. Conclusão semelhante é alcançada em relação à análise da quantidade de investidores que se utilizaram do BVD e ao aumento do engajamento e número de participantes com perfil de investidores estrangeiros, que deixaram de arcar com os custos transacionais relacionados à emissão de procurações, e passaram a adotar o BVD.

Como política pública, entendemos que o engajamento de acionistas com perfil não controlador no exercício de direitos políticos será extremamente virtuoso.

O ativismo societário pode ser visto como elemento positivo na medida em que incentiva os próprios agentes privados das sociedades anônimas realizem, entre si, monitoramento e supervisão de seus respectivos atos e práticas. Na medida adequada, esse ambiente de autofiscalização tende a ser positivo e, como política pública, faz com que a atuação dos agentes privados diminua os números de casos de abuso e desvios de conduta, em que se faz necessária a interferências dos agentes públicos.

Em um ambiente de intensa participação de acionistas, com diferentes perfis, nas Assembleias Gerais, há expectativa de fluxo adequado de informações e incentivos, capaz de permitir que exista monitoramento e supervisão harmônica entre os diversos agentes das sociedades. Além disso, a intensificação do engajamento dos acionistas promove maior legitimação de atos societários praticados, na medida em que haverá participação de maior número de acionistas cientes e participando dos processos decisórios.

Aguardamos com boas expectativas os novos tempos, nos preparando para os desafios que a Era Digital imporá ao Direito Societário e à regulação do Mercado de Capitais no Brasil. 
O esforço é sempre em prol do aprimoramento do Direito Societário e da Regulação do Mercado de Capitais, na certeza de que, de um lado, esta obra jamais estará completa; mas, de outro lado, os estudos sobre o tema são intermináveis e nunca cessarão. 


\section{BIBLIOGRAFIA ${ }^{651}$}

ABID, Luccas Augusto Nogueira; SCHIEFLER, Gustavo Henrique Carvalho. Títulos de Desenvolvimento Social: Utilizando a Lógica do Mercado de Capitais para Financiar Políticas Públicas no Brasil. Revista Digital de Direito Administrativo. São Paulo, p. 69-103. 11 jan. 2016. Disponível em: <http://www.revistas.usp.br/rdda/article/view/106006/108645>. Acesso em 05.11.2019.

ACTUALICESE. “Asambleas y Juntas Virtuales: ¿son legales?, ¿cómo y cuándo se pueden hacer?": 11.02.2010.Disponível em: https://actualicese.com/asambleas-y-juntas-virtuales-sonlegales-como-y-cuando-se-pueden-hacer/. Acesso em 05.11.2019.

ACTUALICESE. “Asambleas y juntas virtuales: legalidad y forma de realizarlas": 24.03.2017. Disponível em: https://actualicese.com/asambleas-y-juntas-virtuales-legalidad-y-forma-derealizarlas/. Acesso em 05.11.2019.

ADAMEK, Marcelo Vieira Von. Abuso de Minoria em Direito Societário. São Paulo: Malheiros, 2014.

Responsabilidade Civil dos Administradores de S/A (e as Ações Correlatas). São Paulo: Saraiva, 2009.

ADMATI, Anat R., PFLEIDERER, Paul. The "Wall Street Walk" and Shareholder Activism: Exit as a Form of Voice, 22, The Review of Financial Studies, 7, 2445-2486 (2009).

ARAGÃO, Paulo Cezar. "A disciplina do acordo de acionistas", In: LOBO, Jorge (coord.). Reforma da Lei das Sociedades Anônimas pp.423-452. Rio de Janeiro: Forense, 2002.

ARMOUR, John, HANSMANN, Henry; e KRAAKMAN, Reinier. The Anatomy of Corporate Law: A Comparative and Functional Approach. $3^{\text {a }}$ ed. Oxford: Oxford University Press, 2017.

ASCARELLI, Tullio. Interpretazione del diritto e studio del diritto comparato, in Saggi di Diritto Commerciale, Milão: Giuffrè, 1995.

AZEVEDO, Antônio Junqueira. Negócio Jurídico - Existência, Validade e Eficácia. $4^{\mathrm{a}}$ ed., $7^{\mathrm{a}}$ Tir. São Paulo: Saraiva, 2002.

AZEVEDO, Luís André N. de Moura. A Nova Corporation: Ativismo Societário e Investidores Institucionais. In. Governança Corporativa. Avanços e Retrocessos. ROSSETTI, Maristela Abla; PITTA, Andre Grunspun (coords). São Paulo: Quartier Latin, 2017.

A oferta pública para aquisição de controle sob a perspectiva da companhia aberta ofertante. In: CASTRO, Rodrigo R. Monteiro; ARAGÃO, Leandro Santos de (coord.), Direito Societário: Desafios Atuais. São Paulo: Quartier Latin, 2009.

BAPTISTA, Conrado Luciano. A Democracia Ateniense Clássica. Revista Filosofia Capital, Brasília - DF, edição 16, v. 9, p. 6-18, 05 dez. 2014. Disponível em:

\footnotetext{
${ }^{651}$ De acordo com a Associação Brasileira de Normas Técnicas (ABNT NBR 6023).
} 
$<$ http://www.filosofiacapital.org/ojs-

2.1.1/index.php/filosofiacapital/article/viewFile/247/221> Acesso em 05.11.2019.

BARROSO, Luís Roberto. Interpretação e aplicação da Constituição: fundamentos de uma dogmática constitucionl transformadora. $7^{\text {a }}$ ed. São Paulo: Saraiva, 2009.

BEBCHUK, Lucian A., The Case for Increasing Shareholder Power. Harvard Law Review, Vol. 118, No. 3, pp. 833-914, Janeiro 2005; Harvard Law and Economics Discussion Paper No. 500. Disponível em SSRN: https://ssrn.com/abstract=387940. Acesso em 05.11.2019.

BEBCHUK, Lucian e WEISBACH. "The State of Corporate Governance Research". In: Fisher College of Business Working Paper No. 2009-03-20; Review of Financial Studies, Vol. 23. No. 3, pp. 939-961, 2010.; Fisher College of Business Working Paper No. 2009-03-20; Harvard Law and Economics Discussion Paper No. 652. Disponível em SSRN: $\underline{\text { https://ssrn.com/abstract=1508146 or http://dx.doi.org/10.2139/ssrn.1508146. Acesso }}$ $\underline{\text { em } 05.11 .2019}$

BEEDHAM, Matthew. "West Virginia to roll out blockchain-powered voting app - but there's a caveat". The Next Web: 07 de agosto de 2018. Disponível em: https://thenextweb.com/hardfork/2018/08/07/blockchain-voting-west-virginia/. Acesso em 05.11.2019.

BERLE, Adolf A.; MEANS, Gardiner C. The Modern Corporation and Private Property. New York: Macmillan, 1932.

BERTOLDI, Marcelo M. Acordo de Acionistas na reforma da lei das Sociedades por Ações. São Paulo: RT, 2006.

BORBA, José Edwaldo Tavares. Direito Societário. 10ª ed. Rio de Janeiro: Renovar, 2007.

BOROS, Elizabeth. Virtual Shareholder Meetings: Who Decides How Companies Make Decisions? Melbourne University Law Review, Vol. 28, № 2, pp. 265-289, 2004. Disponível em: SSRN: 〈https://ssrn.com/abstract=883566>. Acesso em 05.11.2019.

. Virtual Shareholder Meetings, 3 Duke Law \& Technology Review 1-10 (2004).

BOTTOSELLI, Ettore. Assembleia Geral Eletrônica. Revista de Direito Bancário e do Mercado de Capitais, $\mathrm{n}^{\circ}$ 75, 2017.

BOURNE, Nicholas. Bourne on a Company Law. $7^{\text {a }}$ ed. Nova Iorque: Routledge, 2016.

BRANCO, Adriano Castello. "Breves Notas sobre Ofertas Públicas de Ações no Direito Brasileiro e Governança Corporativa". In: SILVA, Alexandre Couto (coord.). Direito Societário: Estudos sobre a Lei de Sociedades por Ações. São Paulo: Saraiva, 2013.

O Conselho de Administração nas Sociedades Anônimas. 2a ed. Rio de Janeiro: Forense Universitária, 2007. 
BULGARELLI, Waldirio. “Deliberar não deliberar é deliberar?'. In: Questões de Direito Societário. São Paulo: RT, 1983.

CAMPBELL, Harvey R.. Cryptofinance (Janeiro 14, 2016). Disponível em SSRN: https://ssrn.com/abstract=2438299. Acesso em 05.11.2019.

CAMPINHO, Sergio. Falência e Recuperação de Empresa: O novo Regime da Insolvência Empresarial. Editora Renovar. Primeira edição. 2006.

CARRANÇA, Thais e SCHINCARIOL, Juliana. "Voto a distância em assembleias gera dúvidas e críticas de investidor", artigo publicado em 19/06/2017 no jornal Valor Econômico. Disponível em: https://valor.globo.com/wallconcurrence/?next=https $\% 3 \mathrm{~A} \% 2 \mathrm{~F} \% 2 \mathrm{Fvalor}$.globo.com\%2Ffinancas\%2Fnoticia\%2F $2017 \% 2$ F06\%2F19\%2Fvoto-a-distancia-em-assembleias-gera-duvidas-e-criticas-deinvestidor.ghtml\&group=desktop. Acesso em 05.11.2019.

CARVALHOSA, Modesto. Comentários à Lei das Sociedades Anônimas. Vol. II - Artigos 75 a 137. $5^{\text {a }}$ ed. São Paulo: Saraiva, 2011.

Comentários à Lei das Sociedades Anônimas. Vol. III - Artigos 138 a 205. $3^{\text {a }}$ ed. São Paulo: Saraiva, 2003.

CARVALHOSA, Modesto; EIZIRIK, Nelson. A nova Lei das S/A. São Paulo: Saraiva, 2002.

CASIUCH, Breno. Ativismo Societário Inc. vs. Ativismo Societário S.A.: Já se pode notar um avanço do ativismo societário no Brasil. Jota: Opinião e Análise, Rio de Janeiro, 2016. Disponível em: <https://www.jota.info/opiniao-e-analise/artigos/ativismo-societario-inc-vsativismo-societario-s-28072016 $>$ Acesso em 05.11.2019.

CASTRO, Rodrigo R. Monteiro de. "Abertura e Fechamento de Capital". In: CASTRO, Rodrigo R. Monteiro; ARAGÃO, Leandro Santos de (coord.). Sociedade Anônima - 30 anos da Lei 6.404/76. São Paulo: Quartier Latin, 2007.

Controle Gerencial. São Paulo: Quartier Latin, 2010.

CHEFFI, Sonia A. Les effets du vote par internet aux assemblées générales des actionnaires sur la gouvernance d'entreprise actionnariale. Recherches em Sciences de Gestion, v. 6, ${ }^{\circ}$ 87, p. 69-92, 2011

CLARK, Robert Charles. Corporate Law. Boston/Toronto: Little, Brown and Company, 1986.

COASE, R. H. "The Nature of the Firm" In: Economica (new series), Vol. 4, No 16, pp. 386405, 1937. Disponível em SSRN: https://ssrn.com/abstract=1506378. Acesso em 05.11.2019.

CODORNIZ, Gabriela; LOPES, Marília. A Representação de Acionista em Assembleia Geral de Sociedade: Observações sobre o Posicionamento da CVM. RSDE. Revista Semestral de Direito Empresarial, v. 13, pp. 83-112, 2013. 
COINDESK. "The Sierra Leone vote: what we got wrong", In: Coin Desk, 26.03.2018. Disponível em: https://www.coindesk.com/blockchain-vote-election-sierra-leone-got-wrong. Acesso em 05.11.2019.

COMPARATO, Fábio Konder. Aspectos Jurídicos da Macroempresa. São Paulo: RT, 1970, pp. 1-10.

. "Da imprescritibilidade da ação direta de nulidade de norma estatutária". In: Novos Ensaios e Pareceres de Direito Empresarial, Rio de Janeiro, Forense, 1981.

COMPARATO, Fábio Konder; e SALOMÃO FILHO, Calixto. O Poder de Controle na Sociedade Anônima. $6^{\text {a }}$ ed. Rio de Janeiro: Forense, 2014.

COOTER, Robert; ULEN, Thomas. Direito \& Economia. Tradução: Luis Marcos Sander, Francisco Araújo da Costa. $5^{\text {a }}$ ed. Porto Alegre: Bookman, 2010.

CRISTÓFARO, Pedro Paulo. "O Empate nas Deliberações das Assembleias Gerais das Companhias". In: VENANCIO FILHO, Alberto; LOBO, Carlos Augusto da Silveira; ROSMAN, Luiz Alberto Colonna (org.). In: Lei das S.A. em seus 40 anos. pp. 331-343. Rio de Janeiro: Forense, 2017.

CSD Working Group on DLT. "General Meeting Proxy Voting on Distributed Ledger Product Requirements", v. 2.1, Novembro de 2017, p. 10. Disponível em: https://www.issanet.org/e/pdf/2017-

11_General_Meeting_Proxy_Voting_on_Distributed_Ledger_v2-1.pdf. $\quad$ Acesso em 05.11.2019.

CVM. Audiência Pública SDM nº 09/2014. Relatório de Análise - Audiência Pública SDM no 09/2014 - Processo CVM nº RJ-2011-13930. Rel. Luciana Dias. Publicado em 07.04.2015. Disponível em: <http://www.cvm.gov.br/export/sites/cvm/audiencias_publicas/ap_sdm/anexos/2014/sdm091 4relatorio.pdf $>$. Acesso em 05.11.2019.

CVM. Memorando SDM nº 13 de 14 de julho de 2017.

CVM. Ofício Circular CVM|SEP no 03/2019, de 28 de fevereiro de 2019. Disponível em: <http://www.cvm.gov.br/legislacao/oficios-circulares/sep/oc-sep-0319.html >. Acesso em 05.11.2019.

DEHONDT, Joseph R. Is it time to switch to virtual shareholder meetings?. Artigo publicado no jornal Lexology, em 27 de janeiro de 2017, disponível em https://www.lexology.com/library/detail.aspx?g=1a4e2429-feb5-4b77-8168-64f9e835ccc1. Acesso em 05.11.2019.

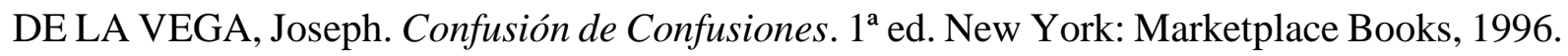


DIAS, Luciana Pires e SILVA, Lucas Santanna de Almeida. Avanços Legais e Regulamentares em Matéria de Participação e Votação a Distância nas Assembleias Gerais de Companhias Abertas. In. Governança Corporativa. Avanços e Retrocessos. ROSSETTI, Maristela Abla; PITTA, Andre Grunspun (coords). São Paulo: Quartier Latin, 2017.

DOMINGUES, Paulo de Tarso. Os meios telemáticos no funcionamento dos órgãos sociais. O regime português". In: Revista semestral de direito empresarial, vol. 10, 2012.

DUTRA, Marcos Galileu Lorena; SAITO, Richard. Conselhos de administração: análise de sua composição em um conjunto de companhias abertas brasileiras. Revista de Administração Contemporânea, vol. 6, $\mathrm{n}^{\mathrm{o}}$ 2. Curitiba. Maio/Agosto, 2002. Disponível em $<$ http://www.scielo.br/scielo.php?script=sci_arttext\&pid=S1415-65552002000200003>. Acesso em 05.11.2019.

EASTERBROOK, Frank H e FISCHEL, Daniel R. The Economic Structure of Corporate Law. Harvard: Harvard University Press, 1948.

EIZIRIK, Nelson. A Lei das S/A Comentada. Volume I - $2^{a}$ Edição Revista e Ampliada Artigos 1 a 79. São Paulo: Quartier Latin, 2015.

A Lei das S/A Comentada. Volume II - 2a Edição Revista e Ampliada - Artigos 80 a 137. São Paulo: Quartier Latin, 2015.

. A Lei das S/A Comentada. Volume III - 2a Edição Revista e Ampliada - Artigos 138 a 205. São Paulo: Quartier Latin, 2015.

Interpretação dos $\S \S 8^{\circ}$ e $9^{\circ}$ do art. 118 da Lei das S/A, In: RDM no 139, 2005, pp. 155-176. São Paulo: Malheiros, 2005.

O mito do "controle gerencial" - alguns dados empíricos. RDM. São Paulo: Malheiros, n. 66, pp.103-106, abr./jun., 1987.

EIZIRIK, Nelson, et al. Mercado de Capitais Regime Jurídico. $3^{\mathrm{a}}$ ed. Rio de Janeiro: Renovar, 2011.

ELESWARAPU, Venkat R.; THOMPSON, Rex; VENKATARAMAN, Kumar. The Impact of Regulation Fair Disclosure: Trading Costs and Information Asymmetry. Journal Of Financial And Quantitative Analysis, Seattle, v. 39, n. 2, pp.209-225, jun. 2004.

EUROPEAN PARLIAMENT. Directorate-General For Policies Policy Department C: Citizens' Rights And Constitutional Affairs. Rights and obligations of shareholders: national regimes and proposed instruments at EU level for improving legal efficiency. Disponível em: <http://www.europarl.europa.eu/meetdocs/2009_2014/documents/juri/dv/pe462463_/pe46246 3_en.pdf $>$. Acesso em 05.11.2019.

EVANS, David S. Economic Aspects of Bitcoin and Other Decentralized Public-Ledger Currency Platforms (April 15, 2014). University of Chicago Coase-Sandor Institute for Law \& 
Economics Research Paper No. 685, p. 03, Disponível em

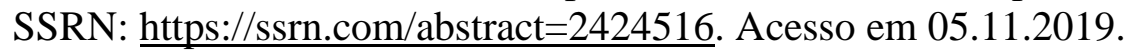

FAIRFAX, Lisa M. Virtual Shareholder Meetings Reconsidered (2010). Seton Hall Law Review, Vol. 40, No 1367, 2010; GWU Legal Studies Research Paper No 539; GWU Law School Public Law Research Paper $\mathrm{N}^{\circ}$ 539. Disponível em: SSRN: $<$ https://ssrn.com/abstract=1787297>. Acesso em 05.11.2019.

Delaware's New Proxy Access: Much Ado About Nothing. Transactions: The Tennessee Journal of Business Law, Tennessee, v. 11, n. 85, p.87-109, jan. 2009. Disponível em: < https://trace.tennessee.edu/transactions/vol11/iss1/8/>. Acesso em 05.11.2019.

FERREIRA, Aurélio Buarque de Holanda. Novo Aurélio do Século XXI: O Dicionário da Lingua Portuguesa. $1^{\text {a }}$ ed. Rio de Janeiro: Nova Fronteira, 1999.

FERREIRA, Waldemar. Tratado de Direito Comercial. v. 4 , São Paulo: Saraiva 1963, p. 810.

Finacial Times. "Santander shows potential of blockchain in company votes", In: Financial Times, 17.05.2018. Disponível em: https://www.ft.com/content/c03b699e-5918-11e8-bdb7$\underline{\mathrm{f} 6677 \mathrm{~d} 2 \mathrm{e} 1 \mathrm{ce} 8}$. Acesso em 05.11.2019.

MAIA, Pedro. Voto e Corporate Governance. Um novo paradigma para a Sociedade Anônima. Coimbra: Almedina, 2019.

FRANÇA, Erasmo Valladão Azevedo e Novaes. Conflito de Interesses nas Assembleias de S.A. $2^{a}$ ed. São Paulo: Malheiros, 2014.

Invalidade das deliberações de assembleia das S/A e outros escritos sobre o tema da invalidade das deliberações sociais. $2^{\mathrm{a}}$ ed, rev. e aum. São Paulo: Malheiros, 2017.

FORÇA TAREFA DE FINANÇAS SOCIAIS. Conquistas e Avanços do Ecossistema de Investimentos e Negócios de Impacto no Brasil. 2018. Disponível em: <https://forcatarefaassets.s3.amazonaws.com/uploads/2019/04/Alianca_Relatorio_2018-com-links.pdf >. Acesso em 05.11.2019.

GALGANO, Francesco. Diritto commerciale. $18^{\circ}$ ed. Turim: Zanichelli Bologna, 2013.

GARNER, Bryan A (coord.). Black's Law Dictionary. 10ª ed. Nova Iorque: Thompson Reuters, 2014.

GEDIEL, José Antônio Peres; CORRÊA, Adriana Espíndola. Proteção Jurídica de Dados Pessoais: A Intimidade Sitiada Entre o Estado e o Mercado. Revista da Faculdade de Direito UFPR, Curitiba, n. 47, pp. 141-153, 2008. Disponível em: <https://revistas.ufpr.br/direito/article/view/15738/10444>. Acesso em 05.11.2019.

GIERKE, Otto von. "Da História do Princípio da Maioria". Traduzido por Nilson Lautenschlager Jr. In: Revista de Direito Mercantil, Industrial, Econômico e Financeiro, São Paulo: Editora Malheiros, vol 166/167, ago. 2013-jul. 2014, pp. 7-22. 
GONÇALVES, Pedro Vilela Resende; CAMARGOS, Rafael Coutinho. Blockchain e 'judge as a service' no direito brasileiro. In: Anais do II Seminário de Governança da Redes e o Marco Civil da Internet. 2017. Disponível em: <http://irisbh.com.br/blockchain-smart-contracts-ejudge-as-a-service-no-direito-brasileiro>. Acesso em 05.11.2019.

GONZALEZ, Gustavo Machado; LOPES, Marília. "Assembleias Gerais nas Companhias Abertas: Visão Geral” In: SIQUEIRA, Marcelo; PEREIRA, Atademes Branco; e TREIGER, José Marcos (coords.). Brasil S/A: Guia de Acesso ao Mercado de Capitais para Companhias Brasileiras. $2^{\text {a }}$ ed. Rio de Janeiro: Donnelley Financial Solutions do Brasil Ltda. (DFIN), 2020, 57-80.

GORANOVA, Maria et al. Corporate Governance Antecedents to Shareholder Activism: a Zero-Inflated Process. Strategic Management Journal, John Wiley \& Sons, Ltd., 38, 2017, p. 421.

GORGA, Erica. Changing the Paradigm of Stock Ownership: From Concentrated Towards Dispersed Ownership? Evidence from Brazil and Consequences for Emerging Countries. 3rd Annual Conference on Empirical Legal Studies Papers. Abr. 2008. Disponível em SSRN:

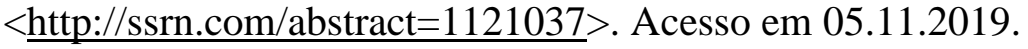

GOUVÊA, Carlos Portugal; e YOSHIKAWA, Caio Henrique. Brazil Shareholders Actvism \& Engagement. Disponível em: https://gettingthedealthrough.com/area/84/jurisdiction/6/shareholder-activism-engagement2019-brazill. Acesso em 05.11.2019.

GOWER, Laurence Cecil Bartlett e DAVIES, Paul Lyndon. Principles of Modern Company Law. $8^{\text {a }}$ ed. Londres: Sweet \& Maxwell, 2008.

GREGORY, H. J., GRAPSAS, R., Holland, C. The Latest on Proxy Access. Harvard Law School Forum on Coporate Governance And Financial Regulation. 2019.

GUERREIRO, José Alexandre Tavares. Sociedade Anônima: Poder e Dominação. Revista de Direito Mercantil, Industrial, Econômico e Financeiro, São Paulo, nº 53, pp. 75-76, jan./mar. 1984.

GUTIÉRREZ, María; SÁEZ, Maribel. Deconstructing Independent Directors, Journal of Corporate Law Studies, 2013, pp. 71. Disponível em <http://dx.doi.org/10.5235/14735970.13.1.63>. Acesso em 05.11.2019.

HABER, Stuart e STORNETTA, W. Scott, "How to Stamp a Digital Document", Journal of Cryptology, vol.3, n.2, pp 99 - 111, 1991.

HILEMAN, Garrick and RAUCHS, Michel. Global Blockchain Benchmarking Study (September 22, 2017), p. 14. 14 Disponível em SSRN: https://ssrn.com/abstract=3040224 or http://dx.doi.org/10.2139/ssrn.3040224. Acesso em 05.11.2019. 
HIRT, Hans-Christoph; JONES, Andy. The Shareholder Rights Directive II, Abril de 2019. Disponível em: < ttps://corpgov.law.harvard.edu/2019/04/04/the-shareholder-rights-directiveii/>. Acesso em 05.11.2019.

HOPT, Klaus J. "Deveres legais e conduta ética de membros do conselho de administração e de profissionais" (trad. port. Erasmo Valladão A. e N. França e Mauro Moisés Kertzer). In: RDM out./dez. 2006. São Paulo: Malheiros, 2006, n. 144, pp. 107-119.

IANSTII, Marco e LAKHANI, Karim R. "Blockchain". In: Merriam-Webster.com. Disponível em <https://www.merriam-webster.com/dictionary/blockchain>. Acesso: 05.11.2019.

IBGC. Instituto Brasileiro de Governança Corporativa. "Caderno de Boas Práticas para Assembleias de Acionistas". In: Cadernos de Governança Corporativa. Vol. 8. São Paulo: IBCG, 2010, p. $14 . \quad$ Disponível em: <https://conhecimento.ibgc.org.br/Paginas/Publicacao.aspx?PubId=21048>. Acesso em 05.11 .2019 .

JENSEN, Michael C.; MECKLING, William H. Theory of the Firm: Managerial Behaviour, Agency Costs and Ownership Structure. Journal of Financial Economics, October, 1976, V. 3, No. 4, pp. 305-360.

KHATRI, Yogita. "Thai Government Agency Develops Blockchain Tech for Elections Voting". Coin Desk: 03 de janeiro de 2019. Disponível em: https://www.coindesk.com/thaigovernment-agencydevelops-blockchain-tech-for elections-voting. Acesso em 05.11.2019.

KHALIQUE, Aqeel; SINGH, Kuldip; SOOD, Sandeep. Implementation of Elliptic Curve Digital Signature Algorithm. In: International Journal Of Computer Applications. Roorkee, pp. 21-27. maio 2010.

KRANS, Anatoli van der. The Virtual Shareholders Meeting: How to make it work? Journal of International Commercial Law and Technology, Vol. 2, Issue 1 (2007).

LAFARRE, Anne; VAN DER ELST, Christoph. Bringing the AGM to the 21st Century: Blockchain and Smart Contracting Tech for Shareholder Involvement (Junho, 2017). European Corporate Governance Institute (ECGI) - Law Working Paper No. 358/2017. Disponível em SSRN: https://ssrn.com/abstract=2992804 or http://dx.doi.org/10.2139/ssrn.2992804. Acesso em 05.11.2019.

. Blockchain Technology for Corporate Governance and Shareholder Activism (March 2018). European Corporate Governance Institute (ECGI) - Law Working Paper No. 390/2018; Tilburg Law School Research Paper No. 2018-7, p.91. Disponível em SSRN: https://ssrn.com/abstract=3135209 ou http://dx.doi.org/10.2139/ssrn.3135209. Acesso em 05.11.2019.

Blockchain Technology for Modernizing the Shareholder Dialogue. Working Paper. Junho de 2018. Disponível em: https://www.tilburguniversity.edu/upload/1413437f-2ccb-4fe9- 
bc01-60aa0c7ec657_BlockchaintechnologyformodernizingshareholderdialogueWP.pdf. Acesso em 05.11.2019.

LAFARRE, Anne. The AGM In Europe: Theory and Practice of Shareholder Behavior. Bingley: Emerald Publishing Limited.

LAMY FILHO, Alfredo; PEDREIRA, José Luiz Bulhões (coord.). Direito das Companhias. $2^{\mathrm{a}}$ ed., atual. e ref. Rio de Janeiro: Forense, 2017.

A Lei das S.A.: pressupostos, elaboração, aplicação. Vol. II. Pareceres. Rio de Janeiro: Renovar, 1996.

"Formação e desenvolvimento das sociedades por ações". In: LAMY FILHO, Alfredo et al. A Lei das S.A. Vol. 1, pp. 19-102. Rio de Janeiro: Renovar, 1997.

LARNER, R. J. "Ownership and Control in the 200 Largest Non-financial Corporation, 1929 and 1963", The American Economic Review, vol. LVI, n 4, $1^{\mathrm{a}}$ parte (setembro de 1966).

LASTER, Vice Chancellor J. Travis. "The Block Chain Plunger: Using Technology to Clean Up Proxy Plumbing and Take Back the Vote Available" Apresentação do Institutional Investors Chicago, realizada em 29 de Setembro de 2016. Disponível em: https://www.cii.org/files/09_29_16_laster_remarks.pdf. Acesso em 05.11.2019.

LA PORTA, Rafael; LOPEZ-DE SILANES, Florencio; SHLEIFER, Andrei; VISHNY, Robert. "Investor Protection and Corporate Governance". In Journal of Financial Economics. V. 58. 2000.

LAZZARESCHI NETO, Alfredo Sérgio. Lei das Sociedades por Ações anotada. $5^{\mathrm{a}}$ edição, revista, atualizada e ampliada. São Paulo: Societatis Edições, 2017, Vol. I.

LEITÃO, Luis Manuel Teles de Menezes. "Voto por correspondência e realização telemática de reuniões de órgãos sociais". In: Jornadas em Homenagem ao Professor Doutor Raúl Ventura. A Reforma ao Código das Sociedades Comerciais. Coimbra: Almedina, 2007.

LOCKE, John. O Segundo Tratado sobre o Governo Civil. Tradução: Magda Lopes e Marisa Lobo da Costa. Editora Vozes: Petrópolis, 1994.

LOSS, Louis. O papel do governo na proteção dos investidores. Revista de Administração de Empresas. Vol. 26. № 2. São Paulo. Abr./Jun. 1986.

Fundamentals of Securities Regulation. Boston, Little, Brown and Company, 1988.

LUCENA, José W. Das Sociedades Anônimas: Comentários à Lei (arts. 121 a 188). Vol. II. Rio de Janeiro: Renovar, 2009.

MACEDO, Ricardo Ferreira de. Controle Não Societário. Rio de Janeiro: Renovar, 2004. 
MÄNTYSAARI, Petri. Comparative Corporate Governance: Shareholders as a Rule-Maker. Springer, 2006.

MARTINS, Fran. Comentários à Lei das Sociedades Anônimas. 4ª ed. Rio de Janeiro: Forense, 2010.

MARTINS RODRIGUES, Jorge José; DOS SANTOS HENRIQUES SEABRA, Fernando Miguel. Conselho de administração: Que funções?. Revista Portuguesa e Brasileira de Gestão, vol. 10, núm. 1-2, janeiro, 2011, pp. 2-12. ISCTE-Instituto Universitário de Lisboa. Lisboa, Portugal. Disponível em <http://www.redalyc.org/pdf/3885/388539127002.pdf>. Acesso em 05.11.2019.

MENEZES, Alfred J.; VANSTONE, Scott A.; OORSCHOT, Paul C. Van. Handbook of Applied Cryptography. 5a ed. Boca Raton: CRC Press, Inc., 2001.

MENEZES, Maurício Moreira Mendonça de. O Poder de Controle nas Companhias em Recuperação Judicial. Rio de Janeiro: Forense, 2012.

MUISYO, Victor. "Kenya electoral body to adopt blockchain technology for vote transparency". Africa News: 21 de Agosto de 2018. Disponível em: https://www.africanews.com/2018/08/21/kenyaelectoral-body-to-adopt-blockchaintechnology-for-vote-transparency/. Acesso em 05.11.2019.

MIRANDA, Pontes de. Tratado de Direito Privado. Parte Especial. Tomo L. Direito das Obrigações: Sociedades por Ações. $3^{\text {a }}$ Ed. Rio de Janeiro: Editor Borsoi, 1972.

MONTESQUIEU. O Espírito das Leis. 9ª ed. Rio de Janeiro: Saraiva, 2008.

MOURA AZEVEDO, Luís André N. de. Ativismo dos Investidores Institucionais e Poder de Controle nas Companhias Abertas da Capital Pulverizado Brasileiras, pp. 218-262. In: MONTEIRO DE CASTRO, Rodrigo R.; MOURA AZEVEDO, Luís André N. de (coord.) Poder de Controle e Outros Temas de Direito Societário e Mercado de Capitais. São Paulo: Quartier Latin, 2010.

MOORE, Andrew G.T. "The Birth of Unocal: A Brief History". In: Delaware Journal of Corporate Law. v. 31, n. 3, 2006, pp. 865-886. Disponível em: $\langle$ http://ssrn.com/abstract=946018 $>$. Acesso em 05.11.2019.

MOREIRA, Vital. Auto-Regulação Profissional e Administração Pública. Coimbra: Livraria Almedina, 1997.

MORGENSON, Gretchen. Meet the Sharesholders? Not at These Shareholder Meetings. Artigo publicado no jornal The New York Times, em 31 de março de 2017, disponível em <https://www.nytimes.com/2017/03/31/business/corporate-virtual-shareholdermeetings.html>. Acesso em 05.11.2019 
MU-HYUN, Cho. "South Korea to develop blockchain voting system". ZDNet: 28 de novembro de 2018. Disponível em: https://www.zdnet.com/article/south-korea-to-develop-blockchainvoting-system/. Acesso em 05.11.2019.

MUNHOZ, Eduardo Secchi. "Desafios do direito societário brasileiro na disciplina da companhia aberta: avaliação dos sistemas de controle diluído e concentrado". In: CASTRO, Rodrigo R. Monteiro; ARAGÃO, Leandro Santos de (coord.). Direito Societário: Desafios Atuais. São Paulo: Quartier Latin, pp. 119-155, 2009.

Empresa Contemporânea e Direito Societário: poder de controle e grupo de sociedades. São Paulo: Juarez de Oliveira, 2002.

MÜSSNICH, Francisco Antunes Maciel. "Voto Plural: quebrando paradigmas", artigo publicado em 15/12/2017 no jornal Valor Econômico. Disponível em: <https://www.valor.com.br/legislacao/5228253/voto-plural-quebrando-paradigmas $>$. Acesso em 05.11.2019.

NAKAMOTO, Satoshi. Bitcoin: A Peer-to-Peer Electronic Cash System. Disponível em $<$ https://bitcoin.org/bitcoin.pdf>. Acesso em 05.11.2019.

NASCIMENTO, João Pedro Barroso do. Medidas Defensivas à Tomada de Controle de Companhias. $2^{a}$ ed. Revista, Ampliada e Atualizada. São Paulo: Quartier Latin, 2019.

NOACK, Ulrich. ARUG II in der Sommerpause - Umsetzung verschoben. Rechtsboard Wirtschafts- und Arbeitsrechtliche Perspektiven. 02.07.2019. Disponível em $<$ https://blog.handelsblatt.com/rechtsboard/2019/07/02/arug-ii-in-der-sommerpauseumsetzung-verschoben/>. Acesso em 05.11.2019.

NOACK, Ulrich. Corporate Governance Kodex 2019: die Hauptversammlung als Stiefkind. Rechtsboard - Wirtschafts- und Arbeitsrechtliche Perspektiven. 25.08.2019. Disponível em $<$ https://blog.handelsblatt.com/rechtsboard/2019/08/25/corporate-governance-kodex-2019die-hauptversammlung-als-stiefkind/> . Acesso em 05.11.2019.

OECD. G20/OECD Principles of Corporate Governance. Paris: OECD Publishing, 2015. Disponível em: 〈https://www.oecd.org/daf/ca/Corporate-Governance-Principles-ENG.pdf $>$. Acesso em 05.11.2019.

OIOLI, Erik Frederico. Regime Jurídico do Capital Disperso na Lei das S.A. São Paulo: Almedina, 2014.

PACHECO, Silvia. "Asambleas de Socios y Sesiones de Junta Directiva Podrán Celebrarse con Presencia Virtual". Punto Jurídico: 20.08.2018. Disponível em: https://www.puntojuridico.com/asambleas-de-socios-junta-directiva-podran-celebrarsevirtualmente/. Acesso em 05.11.2019.

PENTEADO, Mauro Rodrigues. Comentários à Lei de Recuperação e Falência. Capítulo I Disposições Preliminares. In: Francisco Satiro de Souza Jr. e Antonio Sergio A. de Moraes 
Pitombo - coordenadores. Comentários à Lei de Recuperação de Empresas e Falência. $2^{\mathrm{a}}$ ed. São Paulo: RT, 2007.

PEREIRA, Guilherme Döring Cunha. Alienação do Poder de Controle Acionário. São Paulo: Saraiva, 1995.

PERRIER, Arnaud; SCACCHI, Raphaëlle. Les Stratégies anti-OPA. Paris: Economica, 1995.

PIAZZA, Fiammetta S. Bitcoin and the Blockchain as Possible Corporate Governance Tools: Strengths and Weaknesses. Penn State Journal of Law \& International Affairs, Filadélfia, v. 5, p. 262-301, 2017. pp. 293-294.

PILKINGTON, Marc. "Blockchain Technology: Principles and Applications" (September 18, 2015). In: Research Handbook on Digital Transformations, revisado por F. Xavier Olleros e Majlinda Zhegu. Edward Elgar, 2016. Disponível em SSRN: https://ssrn.com/abstract=2662660. Acesso 05.11.2019.

PONTES, Evandro Fernandes de. "Pedido Público de Procuração (Notas Sobre a Representação em Assembleias Gerais de Companhias Abertas no Brasil)". In: ADAMEK, Marcelo Vieira von (coord.). Temas de Direito Societário e Empresarial Contemporâneos. Liber Amicorum Prof. Dr. Erasmo Valladão Azevedo e Novaes França. pp. 327-355. São Paulo: Malheiros Editores, 2011.

RABELO, Carolina Gladyer; e HORTA, Luciana Simões Rebello. "Blockchains na escrituração das Ações das S/A: A Contabilidade Pública Independente". In: Revista de Direito das Sociedades e dos Valores Mobiliários, n. 4, pp. 13-36 nov. 2016.

RABITTE, Pat. "Russia Moving Towards Online Voting”. 150 secs: 09 de março de 2019. Disponível em: https://150sec.com/russia-moving-towards-online-voting/10739/. Acesso em 05.11.2019.

RASKIN, Max. Georgetown Law Tech Review 305 (2017), "The Law and Legality of Smart Contracts", pp. 314. Disponível em: <https://georgetownlawtechreview.org/wpcontent/uploads/2017/05/Raskin-1-GEO.-L.-TECH.-REV.-305-.pdf > . Acesso em 05.11.2019.

REALE, Miguel. Lições Preliminares de Direito. 24a ed. São Paulo: Saraiva, 1999.

REICH, Charles A. “The New Property”. In: The Yale Law Journal, vol. 73, n. 5, abril de 1964, pp. 733-787.

RIBEIRO, Renato Ventura. "Aplicação de Novas Tecnologias nas Assembleias Gerais de Sociedades Anônimas". In: ARAGÃO, Leandro Santos de; CASTRO, Rodrigo R. Monteiro de (coord.). Direto Societário: Desafios Atuais. São Paulo: Quartier Latin, 2009. . Direito de Voto nas Sociedades Anônimas. São Paulo: Quartier Latin, 2009.

RIZZO, Valdo Cestari de; ALMEIDA, Marco La Rosa de. "Do Direito do Acionista à Informação em Companhias Abertas e Fechadas". pp. 594-607 In: ADAMEK, Marcelo Vieira 288 
von (coord.). Temas de Direito Societário e Empresarial Contemporâneos. Liber Amicorum. Prof. Dr. Erasmo Valladão Azevedo e Novaes França. São Paulo: Malheiros Editores, 2011.

ROBERT, Bruno. As Assembleias das S/A: exercício do direito de voto, pedidos públicos de procuração e participação à distância. São Paulo: Singular, 2016.

“A Solicitação da Lista de Acionistas (arts. 126, $\S 3^{\circ}$, e $100, \S 1^{\circ}$ ): legitimação do pedido e limites da discricionariedade da administração da companhia". In: Revista de Direito Mercantil, Industrial, Econômico e Financeiro, vol. 161/162, pp. 100-145, jan./ago. 2012.

. "Proxy Solicitation and Shareholder Director Nominations in Brazil: a comparative analysis of Instrução CVM N. 481/2009". In: Revista de Direito Mercantil, Industrial, Econômico e Financeiro, vol. 155/156, pp. 76-104, ago./dez. 2010.

ROSENFELD, Meni. “Analysis of hashrate-based double-spending” (Fevereiro de 2014). In: ArXiv $n^{o}$ 1402.2009. Disponível em: <https://arxiv.org/abs/1402.2009>. Acesso em 05.11.2019.

SALOMÃO FILHO, Calixto. A Sociedade Unipessoal. São Paulo: Malheiros Editores, 1995. n. 2.3 . O Conselho de Administração na Sociedade Anônima. $2^{\text {a }}$ ed. São Paulo: Atlas, 1999, SALOMÃO NETO, Eduardo. O “trust” e o direito brasileiro. São Paulo: LTr, 1996, n. 5.1.3, pp. 114-115.

SANDULLI, Michele. Capitolo Único. Le Procedure Conconsuali. Sezione I-Lineamenti dele procedure concorsuali. In: Manuale di Diritto Commerciale (coord. Vincenzo Buonocore). 10 ed. Turim: G. Giappichelli, 2011.

SANTOS, Gonçalo Castilho do. "Voto por Correspondência nas Sociedades Anônimas". In: CMVM. Cadernos do Mercado de Valores Mobiliários. vol. 07, abril, 2000.

SAPPINGTON, David E.M., "Incentives in Principal-Agent Relationships", 5, The Journal of Economic Perspectives 2, 45-66 (Spring, 1991).

SCHECHTMAN, David Casz. Potenciais aplicações de blockchain no mercado de capitais (Potential applications of blockchain in capital markets), mimeo, 2019.

SCALZILLI, João Pedro. Mercado de Capitais, Ofertas Hostis e Técnicas de Defesa. São Paulo: Quartier Latin, 2015.

SCHIEFLER, Gustavo Henrique Carvalho e ABID, Luccas Augusto Nogueira. Títulos de Desenvolvimento Social: Utilizando a Lógica do Mercado de Capitais para Financiar Políticas Públicas no Brasil. Revista Digital de Direito Administrativo. São Paulo, p. 69-103. 11 jan. 2016. Disponível em: <http://www.revistas.usp.br/rdda/article/view/106006/108645>. Acesso em 05.11.2019. 
SCHWAB, Klaus. A Quarta Revolução Industrial. Trad. Daniel Moreira Miranda. São Paulo: Edipro, 2016.

SILVA, Alexandre Couto. "Conflito de Interesses: Problemas de Agência". In: SILVA, Alexandre Couto (coord.). Direito Societário: Estudos sobre a Lei de Sociedades por Ações. São Paulo: Saraiva, 2013.

SILVA, Alexandre Couto; e SILVA, Ricardo Villela Mafra A. S., "O blockchain como ferramenta de governança corporativa para redução de custos de agência em sociedades anônimas". In: Direito, Tecnologia e Inovação. PARENTONI, Leonardo (coord.). v. I. Belo Horizonte: 2018.

SILVA, Matthew de. "Denver is trying out a blockchain voting app". Quartz: 08 de março de 2019. Disponível em: https://qz.com/1567759/denver-will-use-voatz-mobile-blockchain-appin-municipalelections/. Acesso em 05.11.2019.

STORCK, Michel. Corporate Governance à la Française - Current Trends. European Company and Financial Law Review, vol. 1, nº1, p. 36-59, abril/2004.

SMITH, Adam. An Inquiry into the Nature and Causes of the Wealth of Nations. Methuen \& Co, London, 1776:439.

SZABO, Nick. “Smart Contracts”. 1994. Nick Szabo’s Papers and Concise Tutorials 6.

Disponível em:

http://www.fon.hum.uva.nl/rob/Courses/InformationInSpeech/CDROM/Literature/LOTwinter school2006

/szabo.best.vwh.net/smart.contracts.html. Acesso em 05.11.2019.

STARR, Chester G. $O$ nascimento da democracia ateniense: A Assembleia no Século $V$ A.C. São Paulo: Odysseus, 2005.

TALARICO, Thamilla. "Blockchain, Transparência e o Direito Societário" In: HANSZMANN, Felipe (org.) Atualidades em Direito Societário e Mercado de Capitais. Vol. III, pp. 467-510. Rio de Janeiro: Lumen Juris, 2018.

TEIXEIRA, Egberto Lacerda; GUERREIRO, José Alexandre Tavares. Das Sociedades Anônimas no Direito Brasileiro. vol. 1. São Paulo: João Bushatsky, 1979.

TELLECHEA, Rodrigo. Autonomia Privada no Direito Societário. São Paulo: Quartier Latin, 2016.

TOKOI, Yuki. "Procuração de voto: o que configura um pedido público?". Capital Aberto, 11.03.2016. Disponível em: <https://capitalaberto.com.br/temas/legislacao-eregulamentacao/procuracao-de-voto-o-que-configura-um-pedido-publico/>. Acesso em 05.11.2019. 
TOLEDO, Paulo Fernando Campos Salles. "Modificações introduzidas na lei de sociedades por ações, quanto à disciplina da administração das companhias" In: LOBO, Jorge (coord.). Reforma da Lei das Sociedades Anônimas, pp.423-452. Rio de Janeiro: Forense, 2002.

TOZETTO, Claudia. "Blockchain: O protocolo da confiança", artigo publicado em 22/04/2017 no jornal Estadão. Disponível em: <https://link.estadao.com.br/noticias/inovacao,blockchaino-protocolo-da-confianca,70001748136>. Acesso em 05.11.2019.

UEDA, Andréa Silva Rasga. As Publicações dos Atos Societários. Jota. 15.08.2019. Disponível em: $\quad$ https://www.jota.info/opiniao-e-analise/artigos/as-publicacoes-dos-atos-societarios$\underline{15082019}$. Acesso em 05.11.2019.

UYSAL, Nur et al. Corporate governance on stakeholder issues: shareholder activism as a guiding force. Journal of Public Affairs, Volume 15 Número 2, 2015.

VALADARES, Silvia Mourthé; e LEAL, Ricardo Pereira Câmara. Ownership and Control Structure of Brazilian Companies. 2000. Disponível em SSRN: $\langle$ http://ssrn.com/abstract=213409 $>$. Acesso em 05.11.2019.

VALOIS, Diego. Título de Ação Social - Uma nova proposta de funding para projetos sociais. Disponível em: <https://www.jota.info/opiniao-e-analise/artigos/titulo-de-acao-social-umanova-proposta-de-funding-para-projetos-sociais-16022016>. Acesso em 05.11.2019.

VERMEULEN, Erik P. M., Corporate Governance in a Networked Age (August 9, 2015). Wake Forest Law Review, 2015 Forthcoming; Lex Research Topics in Corporate Law \& Economics Working Paper No. 2015-4; Tilburg Law Research Paper No. 16/2015. Disponível em: https://ssrn.com/abstract=2641441. Acesso em 05.11.2019.

VILLAÇA, Bianca Fortes. Making Money While Making Difference: perspectivas do investimento de impacto no Brail. In: Coleção Jovem Jurista 2016. Rio de Janeiro: Editora FGV, 2016.

VISENTINI, Gustavo. L'Assemblea Della Società Per Azioni. Roma: Dike, 2017.

WALD, Arnoldo. O Governo das Empresas. Revista de Direito Bancário, do Mercado de Capitais e da Arbitragem, v. 15. São Paulo: Revista dos Tribunais, jan./mar. 2002.

WELLISCH, Julya Sotto Mayor. Mercado de Capitais: Fundamentos e Desafios. São Paulo: Quartier Latin, 2018.

WEY, Alexandra. "Switzerland's first municipal blockchain vote hailed a success". In: Swiss Info: 02.07.2018. Disponível em: https://www.swissinfo.ch/eng/crypto-valley-_-switzerland-sfirst- municipal-blockchain-vote-hailed-a-success/44230928. Acesso em 05.11.2019.

WOLFF, Francis. Aristóteles e a Política. Tradução: Thereza Christina Ferreira Stummer e Lygia Araújo Watanabe, $1^{\text {a }}$ ed., Discurso Editorial: São Paulo, 1999. 
YERMACK, David. Corporate Governance and Blockchains (November 28, 2016). Review of Finance, Forthcoming. Disponível em SSRN: https://ssrn.com/abstract=2700475. Acesso em 05.11.2019.

YOKOI, Yuki. "Clicou, votou: seis questões sobre assembleias virtuais, que serão reguladas pela CVM este ano". In: Revista Capital Aberto n 101, jan. 2012.

ZETZSCHE. Dirk A. School. Corporate Governance in Cyberspace - a Blueprint for Virtual Shareholder Meetings (June 19, 2005). CBC-RPS No. 0011. Disponível em: SSRN: https://ssrn.com/abstract=747347. Acesso em 05.11.2019.

. Virtual Shareholder Meetings and the European Shareholder Rights Directive Challenges and Opportunities (Junho 26, 2007). CBC-RPS No 0029. Disponível em: SSRN: $\langle$ https://ssrn.com/abstract=996434>. Acesso em 05.11 .2019 ou $<$ http://dx.doi.org/10.2139/ssrn.996434>. Acesso em 05.11.2019.

\section{Decisões Administrativas Nacionais}

CVM. Processo Administrativo n ${ }^{\circ}$ 19957.000057/2018-75, Rel. Superintendência de Relações com Empresas - SEP, j. em 30.01.2018.

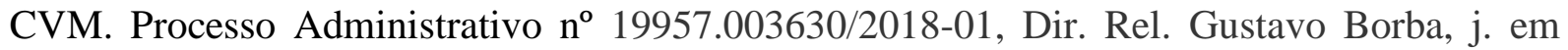
09.10.2019.

CVM. Processo Administrativo no 19957.004385/2019-21, Dir. Rel. Carlos Alberto Rebello Sobrinho, j. 05.11.2019.

CVM. Processo Administrativo no 19957.005749/2017-29, Rel. SEP, j. em 26.09.2017.

CVM. Processo Administrativo no 19957.006903/2016-7, Rel. Henrique Balduino Machado, j. em 12.07.2018.

CVM. Processo Administrativo no RJ 2004/5494, Dir. Rel. Diretor Wladimir Castelo Branco Castro, j. em 16.12.2004.

CVM. Processo Administrativo no RJ 2007/11086, Dir. Rel. Marcos Barbosa Pinto, j. em 06.05.2008.

CVM. Processo Administrativo n ${ }^{\circ}$ RJ 2008/1794, Dir. Rel. Sergio Weguelin, j. em 24.06.2008.

CVM. Processo Administrativo nº RJ 2010/12738. Rel. DOZ, j. 17.05.2011.

CVM. Processo Administrativo nº RJ 2011/13930, Dir. Rel. Luciana Dias, j. em 07.04.2015.

CVM. Processo Administrativo nº RJ 2014/3578. Rel. DAN, j. em 04.11.2014. 
CVM. Processo Administrativo $n^{\circ}$ RJ 2015/10215, Dir. Rel. Henrique Balduino Machado Moreira, j. 20.02.2018.

\section{Decisões Judiciais Nacionais}

BRASIL. Supremo Tribunal Federal, Plenário, Ação Direta de Inconstitucionalidade "ADI n 6.215/DF”, Ministro Relator Marco Aurélio, ainda sob julgamento.

BRASIL. Superior Tribunal de Justiça, 4a Turma, Recurso Especial "REsp: 362778/RS", Mininistro Relator Sálvio De Figueiredo Teixeira, julgado em 13 de maio de 2003.

BRASIL. Superior Tribunal de Justiça, Quarta Turma, Recurso Especial "REsp: 654496 RJ”, Ministro Relator João Otávio De Noronha, julgado em 05 de novembro de 2009.

BRASIL. Superior Tribunal de Justiça, Terceira Turma, Recurso Especial "Resp no 1152849/MG”, Ministro Relator João Otávio de Noronha, julgado em 07 de novembro de 2013.

BRASIL. Superior Tribunal de Justiça, Quarta Turma, Recurso Especial "REsp: 1330021 SP 2012/0025233-6”, Relator: Ministro Luis Felipe Salomão, 17 de março 03 de 2016.

BRASIL. Superior Tribunal de Justiça. AREsp nº 1.274.629, PR 2018/0079362-8. Min. Rel. Maria Isabel Gallotti, julgado em 04 de junho de 2018.

DISTRITO FEDERAL. Tribunal de Justiça, $1^{\mathrm{a}}$ Turma Cível, Apelação $\mathrm{n}^{\mathrm{o}}$ 001042640.2012.8.07.0015, Desembargador Relator Flavio Rostirola, julgado em 18 de setembro de 2013.

MINAS GERAIS. Apelação Cível no 200000051595390001， 15 a Câmara Cível, Desembargador Relator: Mota e Silva, julgado em 09 de setembro de 2005.

\section{Decisões Judiciais Estrangeiras}

Hoge Raad, ASMI International N.V. v. acionistas, caso n. 228, julgado em 4 de julho de 2010, julgado em 4 de julho de 2010.

English Court of Appeal, Byng v London Life Ass'n Ltd., 1990 Ch. 170, 183 (C.A.).

U.S. Supreme Court, Hall v. Geiger-Jones Co., caso n. 438, julgado em 22 de janeiro de 2017, publicado no U.S. Report n. 242, p. 539, citado em KARMEL, Roberta S., 28 Brook. J. Int'1 L. 495 (2002-2003).

U.S. Supreme Court, Hines v. Davidowitz, caso n. 22, julgado em 20 de janeiro de 1941, publicado no U.S. Report n. 312, p. 52, citado em U.S. Court of Appeals, 9th Circuit, Jones v. Rath Packing Co., caso n. 75-1053, julgado em 29 de março de 1977, publicado no U.S. Report n. 430 , p. 519.

U.S. Court of Appeals, 9th Circuit, Whistler Investments, Inc. v. The Depository Trust and Clearing Corporation, caso n. 06-16088, julgado em 22 de agosto de 2008, U.S. Report n. 539. 